Utah State University

DigitalCommons@USU

$6-12-2020$

\title{
Measuring Channel Planform Change From Image Time Series: A Generalizable, Spatially Distributed, Probabilistic Method for Quantifying Uncertainty
}

\author{
Christina M. Leonard \\ Utah State University, christina.leonard@aggiemail.usu.edu \\ Carl J. Legleiter \\ U.S. Geological Survey \\ Devin M. Lea \\ University of Oregon \\ John C. Schmidt \\ Utah State University, jack.schmidt@usu.edu
}

Follow this and additional works at: https://digitalcommons.usu.edu/wats_stures

Part of the Environmental Sciences Commons

\section{Recommended Citation}

Leonard, C. M., Legleiter, C. J., Lea, D. M., and Schmidt, J. C. (2020) Measuring channel planform change from image time series: A generalizable, spatially distributed, probabilistic method for quantifying uncertainty. Earth Surf. Process. Landforms, https://doi.org/10.1002/esp.4926.

This Article is brought to you for free and open access by the Watershed Sciences Student Works at DigitalCommons@USU. It has been accepted for inclusion in Watershed Sciences Student Research by an authorized administrator of DigitalCommons@USU. For more information, please contact digitalcommons@usu.edu.

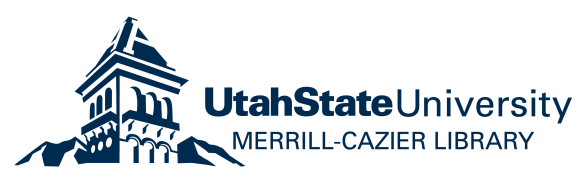




\section{Measuring channel planform change from image time series: A generalizable, spatially distributed, probabilistic method for quantifying uncertainty}

Revised manuscript submitted to Earth Surface Processes and Landforms

Christina M. Leonard ${ }^{1}$, Carl J. Legleiter ${ }^{2}$, Devin M. Lea ${ }^{3}$, John C. Schmidt ${ }^{1}$

${ }_{1}^{1}$ Department of Watershed Sciences, Utah State University, 5210 Old Main Hill, Logan, UT 84322-5210

${ }^{2}$ U.S. Geological Survey, Integrated Modeling and Prediction Division, Golden, CO 80403

${ }^{3}$ Department of Geography, University of Oregon, 1251 University of Oregon, Eugene, OR 97403-1251

*corresponding author christina.leonard@aggiemail.usu.edu

Key words: channel change, remote sensing, change detection uncertainty, probabilistic, fluvial geomorphology 


\section{Abstract}

Channels change in response to natural or anthropogenic fluctuations in streamflow and/or sediment supply and measurements of channel change are critical to many river management applications. Whereas repeated field surveys are costly and time consuming, remote sensing can be used to detect channel change at multiple temporal and spatial scales. Repeat images have been widely used to measure long-term channel change, but these measurements are only significant if the magnitude of change exceeds the uncertainty. Existing methods for characterizing uncertainty have two important limitations. First, while the use of a spatially variable image co-registration error avoids the assumption that errors are spatially uniform, this type of error, as originally formulated, can only be applied to linear channel adjustments, which provide less information on channel change than polygons of erosion and deposition. Second, previous methods use a level-of-detection (LoD) threshold to remove non-significant measurements, which is problematic because real changes that occurred but were channel change. Using a case study from the Yampa River, Colorado, we show that the SDP method reduced the magnitude of uncertainty and enabled us to detect smaller channel changes as significant. Additionally, the distributional information provided by the SDP method allowed us to report the magnitude of channel change with an appropriate level of confidence in cases where a simple LoD approach yielded an indeterminate result. 


\section{Introduction}

Despite recent advancements in remote sensing platforms, historic aerial images remain invaluable in the analysis of long-term channel change. These data are windows into the past, providing a rich, spatially robust history of channel change during the $\sim 100$ years since the first air photos were taken (Rhoades et al., 2009; Comiti et al., 2011; Bollati et al., 2014). Programs like Google Earth are a powerful means to visualize channel evolution, because a sequence of aerial images can be easily compared. Although such programs facilitate the casual inspection of channel evolution, they cannot be used to make the precise measurements of channel change that are required for most management applications. Additionally, the aerial and/or satellite images available in these programs only date to the mid-1990s and thus provide only a limited window to the past. Thus, programs like Google Earth cannot entirely replace detailed analyses of channel change that involve geo-referencing and overlaying historic aerial images to quantify changes in channel location over time.

\section{Predicting channel change is a longstanding problem in the field of} geomorphology. Since the mid-20 th century, water resource development and climate change have significantly altered the flow and sediment supplied to most of the world's rivers (Nilsson et al., 2005; Schmidt and Wilcock, 2008; Best, 2019), creating a societal need to understand how such disturbances affect flood risk, ecosystem management and rehabilitation, and land use planning. Case studies of channel change - how much, at what rate, and why - are the primary means of understanding the trajectory of channel adjustment after a disturbance. In many cases repeat aerial images are the only record of the pre-disturbed channel and thus provide the most complete record of 
50 the channel's response. Therefore, studies of channel change using historic aerial

51 images remain of fundamental interest to geomorphologists and those tasked with

52 effectively managing river systems.

Channel change measured from aerial images is only significant if the magnitude of bank erosion or floodplain formation exceeds the magnitude of uncertainty in the channel change analysis (Downward et al., 1994). The existing body of channel change literature includes numerous case studies that use a wide range of methods, which vary

57 in rigor and complexity, to quantify this uncertainty. As a result and for a given case study, one might conclude that the channel changes identified are, or are not, significant depending on how the uncertainty of that analysis is quantified. The simplest methods assume that the magnitude of uncertainty is negligible compared to the magnitude of channel change and can be disregarded (e.g., Lyons et al., 1992; Merritt and Cooper, 2000; Buckingham and Whitney, 2007; Magilligan et al., 2008; Cadol et al., 2011; Comiti et al., 2011; Schook et al., 2017; Wellmeyer et al., 2005), or assume that the uncertainties compensate for one another in the calculation of net channel change and can be disregarded (Gaeuman et al., 2003; Ham and Church, 2000). A more complex approach to quantifying uncertainty is to establish a level-of-detection (LoD); measurements of channel change that are smaller in magnitude than this threshold cannot be distinguished from uncertainty and are removed from the analysis (Urban and Rhoads, 2003). In most studies, the LoD is specified as a spatially uniform threshold for designating measurements as non-significant and excludes these measurements from the analysis (Winterbottom and Gilvear, 2000; White et al., 2010; Martin and Pavlowsky, 2011; Kessler et al., 2013). This approach causes a large number of small planform 
73 changes to be removed from the analysis and introduces a bias by ignoring polygons of

74 very small channel change, implying that the reach-scale average will be dominated by

75 polygons of larger channel change. Lea and Legleiter (2016) partially overcame this

76 limitation by allowing the LoD to vary spatially based on local estimates of image co-

77 registration error, which resulted in a larger proportion of measurements being retained as statistically significant and thus improved the ability to detect actual channel change.

Despite an abundance of methods used to quantify the uncertainty in measurements of channel change from aerial images, a generalizable, robust methodology is lacking. Several metrics are used to measure channel change from repeat aerial images, and previous methods to quantify uncertainty have varied depending on the metric of channel change used in individual case studies. This situation has hindered the development of a generalizable uncertainty method and makes comparing case studies of channel change from image time series more difficult and imprecise than studies of repeat topography, for which generalizable methods for characterizing uncertainty have been developed (Brasington et al., 2003; Wheaton et al., 2010). For example, although the method developed by Lea and Legleiter (2016) (hereafter referred to as the spatially variable registration error (SVRE) method) was a significant improvement upon spatially uniform methods of quantifying image coregistration error, this method can only be applied to linear channel adjustments, such as comparison of channel centerlines for measuring rates of meander migration (Nanson and Hickin, 1983; Micheli and Kirchner, 2002; Schook et al., 2017; Donovan and Belmont, 2019) or bank lines for measuring rates of bank retreat (Urban and Rhoads, 2003; De Rose and Basher, 2011; Day et al., 2013; Kessler et al., 2013). An 
alternative to this simplified linear representation of channel form involves analyzing the area of bank erosion and/or floodplain formation by delineating polygons of erosion and deposition (Gaeuman et al., 2003; Grams and Schmidt, 2005; White et al., 2010;

Swanson et al., 2011; Nelson et al., 2013; Nardi and Rinaldi, 2015). Polygons of erosion and deposition are often a more informative measure of channel change, because these polygons can be used to characterize fundamental attributes of channels (e.g., lateral channel stability) and evaluate the processes by which channels change size. An uncertainty method that allows for spatially varying image co-registration error and can be applied to both linear and areal metrics of channel change thus would be useful.

Another significant limitation of the SVRE and other uncertainty methods is the removal of any channel change measurements smaller than a specific threshold. This LoD approach is problematic, because measured changes less than the specified threshold are assumed to not represent real change and are removed from the analysis. However, including as many measurements of channel change as possible, whether small or large, is important, because those data contribute to our understanding of the processes and mechanisms by which channels adjust. Additionally, the cumulative effect of many small measurements of change might be larger than the effect of a few measurements of large change; thus, excluding small measurements might give the false impression that the channel's response is to adjust in a few areas dominated by large change. Also, preferentially removing small changes could lead to biased removal of erosional areas, because erosion tends to be more spatially focused than deposition (Brasington et al., 2003). Similar concerns with the LoD threshold also exist when estimating volumes of erosion and deposition from two topographic surfaces 
119 (Brasington et al., 2003; Anderson and Pitlick, 2014; Leonard et al., 2017; Anderson,

120

121

122

123

124

125

126

127

128

129

130

131

132

133

134

135

136

137

138

2019). In this case, the LoD threshold tends to preferentially remove polygons of

deposition, because deposition occurs as relatively thin deposits over large areas (e.g., bars) whereas polygons of erosion are typically localized and thick (Brasington et al., 2003). In some instances, the biased removal of deposition can cause the true value of volumetric change to fall outside the $95 \%$ confidence interval of the volumetric change obtained by removing measurements below the LoD threshold (Anderson, 2019).

In this study, we introduce a generalizable method for quantifying the uncertainty associated with measurements of channel change from repeat aerial images based on spatially varying estimates of uncertainty; we call this the Spatially Distributed Probabilistic (SDP) method. The SDP method can be applied to all metrics of channel change calculated from the comparison of repeat aerial images, making this technique the first robust, generalizable method for quantifying uncertainty in measurements of channel change from an image time series. Moreover, the SDP approach provides a probability distribution of planform change as output, rather than a single value with an associated uncertainty, and thus allows the user to estimate the probability that net change was erosional, depositional, or within a specified tolerance of a net sediment balance (i.e., zero net flux).

\section{Spatially distributed probabilistic (SDP) method of quantifying the uncertainty} associated with change detection from an image time series

The purpose of this section is to provide a general overview of the SDP method. Step-by-step instructions for implementing the method can be found in the supplemental information, and both a standalone application and the corresponding MATLAB $®$ source 
142 code for performing an SDP uncertainty analysis are available at

143 https://qcnr.usu.edu/coloradoriver/files/leonard data.

The SDP method considers one source of error - image co-registration - and two sources of uncertainty - digitization and interpretation - in measurements of channel

146 change from repeat aerial images. We define a source of error as having a deviation

147 from a known value and a source of uncertainty as having a range of values that encompass the true measurement. Unlike previous methods that consider multiple sources of error and uncertainty in channel change analysis, the SDP method does not use error propagation to derive a single value to summarize the uncertainty. Instead,

151 each source of error and uncertainty is used to create a probabilistic delineation of the 152 active channel boundary for each of the two images from which a distribution of channel 153 change measurements can be derived.

\subsection{Image co-registration error}

Image co-registration error is related to misalignment in image overlays that can mask real channel change or give a false impression of change when none has

157 occurred (Gaeuman et al., 2005). Image misalignment originates from the need to transform the original row, column pixel coordinates of each digital image to a real-world

159 coordinate system (e.g., a Universal Transverse Mercator (UTM) projection). This process is referred to as image warping and involves finding pairs of identifiable

161 features on an image whose pixel coordinates are in a row, column, or arbitrary local

162 system, referred to as the warp image, and an image that already has been geo-

163 referenced to the desired real-world coordinate system, referred to as the base image.

164 These pairs of points are termed tie-points and are used to establish a spatial 
165 transformation that relates pixel coordinates in the warp image to map coordinates in 166 the base image.

The SDP method uses a spatially distributed image co-registration error that is similar to that of the SVRE method, but we use independent test-points as recommended by Hughes et al. (2006) instead of using tie-points to generate the error surface. Test-points are identified by extracting the map coordinate of the same feature on the image that is being digitized and the most recent image in the time series (Figure

1721 ; step 1a). Test-points differ from tie-points in that test-points are extracted from two 173 images that are geo-referenced to a common coordinate system, and thus directly 174 measure image overlay error rather than the residual error in the transformation used 175 for image warping. Test-points also can be used to quantify co-registration error in 176 images that are already geo-referenced and thus do not require warping, such as data 177 acquired through the National Agriculture Imagery Program (NAIP) or from various 178 satellite platforms. The magnitude of each test-point error is calculated in the $X$ and $Y$ 179 directions by subtracting the test-point coordinate in the image being used to delineate 180 the channel boundary $\left(x_{i}^{\prime}, y_{i}^{\prime}\right)$ from the same test-point coordinate in the most recent 181 image $\left(x_{i}, y_{i}\right)$ (Figure 1 step 1b; Figure $2 \mathrm{a}, \mathrm{b} ;$ ):

$$
\begin{aligned}
& \varepsilon_{x i}=x_{i}-x_{i}^{\prime} ; \#(1) \\
& \varepsilon_{y i}=y_{i}-y_{i}^{\prime} ; \#(2)
\end{aligned}
$$

184 where $\varepsilon_{x i}$ is the magnitude of co-registration error in the $\mathrm{X}$ direction for the $i^{\text {th }}$ test-point 185 and $\varepsilon_{y i}$ is the magnitude of co-registration error in the $\mathrm{Y}$ direction for the $i^{\text {th }}$ test-point. A 186 continuous surface of $\varepsilon_{x}$ and $\varepsilon_{y}$ is then created by triangulating between each $\varepsilon_{x i}$ and $\varepsilon_{y i}$ 
187 point and using bi-linear interpolation within each triangle (Amidror, 2002; Figure 2 a,b).

188 The triangulation is dependent on the spatial distribution of the test-points, however, 189 and we account for this dependency by repeatedly withholding $10 \%$ of the test-points 190 using a 10-fold cross-validation to generate $10 \varepsilon_{x}$ and $\varepsilon_{y}$ surfaces (Figure 1 step 1c-e).

\subsection{Interpretation uncertainty}

Uncertainty in deciphering whether an alluvial surface is part of the active channel or part of the floodplain was originally discussed by Winterbottom and Gilvear (1997), but this aspect of uncertainty is rarely included in studies of channel change. Common indicators used to classify a surface as channel or floodplain include breaks in slope or the elevation of the surface relative to the surrounding floodplain. Such topographic features can only be identified in aerial images when viewed in stereo, but most studies of channel change delineate channel boundaries based on single images (i.e., not stereo pairs) examined within a geographic information system (GIS) software environment. Therefore, the location of the channel boundary is often inferred on the basis of vegetation density (Dean and Schmidt, 2011; Nelson et al., 2013) rather than topographic changes at the edge of the active channel. These delineations thus are subject to greater uncertainty than if image pairs were analyzed in stereo. Using vegetation density as a threshold for defining the edge of the channel is also problematic, because fast-growing perennial vegetation can encroach upon low elevation bars that are regularly inundated during the annual flood but exposed for long 207 periods during base flow. 
210 boundaries (Figure 1 step 2); Dean and Schmidt $(2011,2013)$ used a similar approach.

211 We define the maximum active channel boundary $\left(A_{\max }\right)$ as the smallest extent of the

212 vegetated islands and the largest extent of the active channel and the minimum active

213 channel boundary $\left(A_{\min }\right)$ as the largest extent of the vegetated islands and the smallest

214 extent of the active channel (Figure 3). Thus, $A_{\max }$ represents the maximum area of the

215 active channel whereas $A_{\min }$ represents the minimum area of the active channel.

\section{2.3. Digitization uncertainty} same operator can repeatedly delineate the same boundary (Gurnell et al., 1994;

219 Micheli and Kirchner, 2002; Donovan et al., 2019) and previously has been quantified 220 using a single value, such as half the product of the width of a pencil line and the scale 221 of the aerial image (Ham and Church, 2000; Gaeuman et al., 2003; Nelson et al., 2013).

222 When digitizing the channel extent on an aerial image, the digitizing uncertainty is not 223 uniform throughout the image and we account for this variability in the SDP method by 224 characterizing the uncertainty probabilistically using a normal distribution with a mean of 225 zero and a standard deviation assumed to be one-third of the maximum digitizing 226 uncertainty. The maximum digitizing uncertainty can be estimated on a case-by-case

227 basis by repeatedly delineating the same boundary or using the image scale and pencil 228 width. Alternatively, the maximum digitizing uncertainty can be assumed to be similar to 229 that of previous studies and taken to be a constant value, such as $2 \mathrm{~m}$ ( e.g., Legleiter, 230 2014; Lea and Legleiter, 2016; Donovan et al, 2019).

231 2.4. Implementation of the SDP method 
The SDP method creates a probabilistic delineation of the active channel

233

234

235

236 237 given by:

238

239

240

241

242

243

244

245

246

247

248

249

250

251

252

boundary using information on all three sources of error and uncertainty described

above: image co-registration, interpretation, and digitization. First, the method adjusts the $A_{\max }$ and $A_{\min }$ boundaries based on the local co-registration error by moving each vertex $\left(x_{j}, y_{j}\right)$ along a vector whose magnitude $\left(\left\|\overrightarrow{\varepsilon_{x y}}\right\|\right)$ and direction $(\theta)$ (Figure 2c) are

$$
\begin{gathered}
\left\|\overrightarrow{\varepsilon x y}_{\vec{x}}\right\|=\left(\varepsilon_{x j}{ }^{2}+\varepsilon_{y j}{ }^{2}\right)^{0.5} ; \#(3) \\
\theta=\tan ^{-1}\left(\frac{\varepsilon_{y j}}{\varepsilon_{x j}}\right) ; \#(4)
\end{gathered}
$$

where $\varepsilon_{x j}$ and $\varepsilon_{y j}$ are the co-registration errors at point $\left(x_{j}, y_{j}\right)$ extracted from the $\varepsilon_{x}$ and $\varepsilon_{y}$ surfaces (Figure 4a). This procedure is repeated for each of the 10 co-registration error surfaces to create $10 A_{\max }$ and $A_{\min }$ boundaries (Figure 1 step 3 ). Along each of the $10 A_{\max }$ and $A_{\min }$ boundaries, a band of delineations that represents digitizing uncertainty is generated by randomly sampling 100 digitization uncertainty values from the normal distribution and moving each vertex along a normal vector by the magnitude of the sampled uncertainty value (Figure 1 step 4; Figure 4b). The final probabilistic delineation for each $A_{\max }$ and $A_{\min }$ boundary consists of 1,000 delineations whose distribution represents co-registration and digitization uncertainty (Figure 4c).

After the probabilistic delineations for $A_{\max }$ and $A_{\min }$ boundaries are created for two aerial images (Figure 1 step 5), probability distributions of channel change are calculated by randomly sampling, with replacement, 5,000 $A_{\max }$ or $A_{\min }$ delineations from both aerial images and overlaying each sampled boundary to create polygons of 
253 erosion and deposition (Figure 1 step 6). This step is performed separately for each

254 combination of $A_{\max }$ and $A_{\min }$ overlays, creating a total of 20,000 calculations of channel

255 change (Figure 1 steps 7a-d): (a) minimum active channel boundary in both images

$256\left(A_{\operatorname{Min}(11)} \& A_{\operatorname{Min}(t 2)}\right)$; where the subscripts $t 1$ and $t 2$ denote the earlier and later images,

257 respectively; (b) maximum active channel boundary in both images $\left(A_{\operatorname{Max}(11)} \& A_{\operatorname{Max}(t 2)}\right) ;(c)$

258 minimum active channel boundary in the earlier image and maximum active channel

259 boundary in the later image $\left(A_{\operatorname{Min}(11)} \& A_{\operatorname{Max}(t 2)}\right)$; and $(d)$ maximum active channel boundary

260 in the earlier image and minimum active channel boundary in the later image

$261\left(A_{\operatorname{Max}(11)} \& A_{\operatorname{Min}(22)}\right)$. The distribution of areal changes for all combinations of overlays

262 represents the combined uncertainty in co-registration, digitization, and interpretation.

The same method can be used to create a probabilistic delineation of channel

264 centerlines or bank lines to obtain a distribution of centerline migration or bank retreat

265 rates. Here, we focus on applying the SDP method to polygons of erosion and

266 deposition because, as discussed in section 1, these measurements yield more

267 geomorphic information.

\section{3. Channel change case study}

To illustrate how the SDP method can be applied in a specific channel change

270 analysis, we describe application of the SDP method to a 23-km alluvial segment of the

271 Yampa and Little Snake Rivers in northwestern Colorado, USA. Here, we describe our

272 analysis of channel change based on analysis of aerial images collected in 1954 and

2731961 (Figure 5). We demonstrate the advantages of the SDP method by comparing our

274 results to those obtained using two methods that do not use a spatially variable image

275 co-registration error and do not characterize uncertainty in a probabilistic manner. The 
276 data used in this case study are available from the U.S. Geological Survey (USGS)

277 ScienceBase (Legleiter and Leonard, 2020). Both historical images were collected from

278 late August to early September at base flow (i.e., 7.16 and $9.03 \mathrm{~m}^{3} \mathrm{~s}^{-1}$ in 1954 and

279 1961, respectively, estimated at the Deerlodge gage by summing the discharge at the Maybell (USGS station number: 09251000) and Lily (USGS station number: 09260000)

281 gages); Figure 5). The flow regimes of the Yampa and Little Snake Rivers are largely 282 unregulated and dominated by spring snowmelt floods. The mean annual flood at the 283 Deerlodge gage is $408 \mathrm{~m}^{3} \mathrm{~s}^{-1}$, and late summer is a time of low discharge (Manners et 284 al., 2014; Topping et al., 2018). Both rivers in the study area have wide active channels with many active bars, as well as bars adjacent to the channel that were formed by 286 floods of different magnitudes. The Little Snake River is the primary source of fine 287 sediment to the Yampa River in Yampa Canyon in Dinosaur National Monument 288 (Topping et al., 2018) and provides a disproportionately large supply of fine sediment 289 relative to the river's contribution of streamflow (Andrews, 1980). We selected this 290 location for our channel change case study, because the National Park Service is 291 concerned about the maintenance of valued park resources that might be affected by 292 upstream water development and recognizes the need to distinguish natural patterns of 293 channel change from changes associated with anthropogenic perturbations.

\subsection{Channel change case study methods}

The 1954 and 1961 images were not geo-referenced to a projected coordinate system, so we warped both images to a common projected coordinate system using the 2972017 NAIP image as a base. The 1954 and 1961 images were downloaded from the 298 USGS Earth Explorer website (USGS, 2019) as 24 single frame images. In Section 2, 
299 we described the general process of image warping whereby tie-points are identified on an individual single frame image to develop a transformation equation for warping that particular image. In this case study, however, we used a Structure-from-Motion (SfM) software package (Agisoft LLC, 2016) to first align and merge the single frame images into a mosaic and then warp and rectify the mosaic by using 12 tie-points with elevations extracted from the National Elevation Dataset (USGS, 2012) to define a 7parameter similarity transformation with three parameters for translation, three for rotation, and one for scaling. Other studies have demonstrated the utility of using SfM to reconstruct elevation models of landforms from historic aerial images (Riquelme et al., 2019), and we found that the same method was useful for geo-referencing a large number of historic aerial images; however, difficulties may arise when the overlap between adjoining images is small. Also, we avoided the misalignments that can occur at the seams of the images when they are individually geo-referenced and overlaid by using SfM to geo-reference the mosaic rather than the individual images (e.g., Donovan et al., 2019). registration error in our case study. These test-points indicated how well the 1954 and 1961 images overlaid on the 2017 NAIP image. In our case study, test-points were 317 difficult to visually identify, because roads and buildings in the 2017 image were not 318 present in the 1954 and 1961 images and "soft" tie-points were limited. Therefore, we used an area-based matching algorithm in the remote sensing software package $E N V I \circledast$ (L3Harris Geospatial) to automatically generate test-points (Figure 2a). The area-based matching algorithm compared grayscale values of each image within a moving search 
322 window and identified similarities and patterns using normalized cross-correlation. We

323 removed test-points with correlation coefficients of less than 0.8 , and we manually

324 inspected the remaining test-points with the lowest correlation coefficients to ensure

325 test-point accuracy. The algorithm produced approximately 450 test-points in both

326 images, but the points were predominantly located on adjacent hillslopes with high

327 textural variability, because the landscape in our case study was rural with high

328 topographic variability. Therefore, we supplemented the ENVI-generated test-points

329 with manually selected points along the valley bottom.

We used the methodology described in Section 2 to create spatially distributed $\varepsilon_{x}$

331 and $\varepsilon_{y}$ surfaces from the test-points generated above and calculate $\left\|\rightarrow{\overrightarrow{\varepsilon_{x y}}}_{\|}\right\|$and $\theta$ at any $x_{j}$,

$332 y_{\mathrm{j}}$ point (Figure 1 steps 1 and 3 ). The spatially uniform root mean square error (RMSE)

333 was calculated using a subset of test-points from our case study that were close to the

334 active channel as: $R M S E=\left[\frac{\sum_{j=1}^{n} \varepsilon_{j}^{2}}{n}\right]^{0.5}, \#(5)$

where $n$ is the number of test-points and $\varepsilon_{j}$ is the linear distance between the $j^{\text {th }}$ test-

336 point in the transformed warp image $\left(x_{j}^{\prime}, y_{j}^{\prime}\right)$ and the base image $\left(x_{j}, y_{j}\right)$, calculated as:

$$
\varepsilon_{j}=\left[\left(x_{j}-x_{j}^{\prime}\right)^{2}+\left(y_{j}-y_{j}^{\prime}\right)^{2}\right]^{0.5}
$$

338 We used a subset of test-points close to the active channel to eliminate the influence of 339 unusually large test-point errors located on adjacent hillslopes that were automatically 340 selected by the area-based matching algorithm and would not have affected channel 341 change measurements. The RMSEs for 1954 and 1961 were 4.95 and $4.52 \mathrm{~m}$, 342 respectively. We assumed that the maximum digitizing uncertainty in our case study 
343 was $2 \mathrm{~m}$ based on previous studies (Donovan et al, 2019) and defined the digitizing 344 uncertainty using a normal distribution with a mean of zero and a standard deviation of 2/3, as described in Section 2 (Figure 1 step 4).

Interpretation uncertainty was estimated by separately digitizing the minimum and maximum extent of the active channel and vegetated islands (Figure 1 step 2). For our case study, we used an initial threshold of $10 \%$ vegetation density to classify surfaces as channel (<10\% vegetation density) or floodplain ( $>10 \%$ vegetation density). However, we were uncertain in several locations whether a surface with $>10 \%$

351 vegetation had aggraded to a height similar to that of the surrounding floodplain with 352 denser, more mature vegetation because the images were not viewed in stereo. This 353 sort of uncertainty is inevitable in any channel change study but the $A_{\min }$ and $A_{\max }$ 354 boundaries described in Section 2 provided a means of classifying these uncertain 355 surfaces as both active channel and floodplain.

We also used a sequence of aerial images that were collected before and after the 357 image being digitized to help us understand the evolution of alluvial surfaces with 358 interpretation uncertainty through time. For example, if an ambiguous surface showed a 359 clear evolution from an unambiguous active channel in the earlier image to unambiguous floodplain in the later image, we knew that during the image sequence the surface changed from channel to floodplain and assumed that the ambiguous surface in 362 the intermediate image being digitized was within this gradual transition. In this 363 instance, we would use the $A_{\min }$ and $A_{\max }$ bounds to classify the surface as both channel 364 and floodplain. Conversely, if the surface was unambiguously active channel in both the 365 earlier and later images, we would assume that the surface in the intermediate image 
366 being digitized was also active channel and the increase in vegetation on that surface

367 might have been caused by the proliferation of vegetation on bars during a period when 368 the annual snowmelt floods were small.

Figure 6 presents two examples from our case study where we used a sequence of 370 aerial images to guide our interpretation of ambiguous alluvial surfaces. The partly

371 vegetated surface in Figure $6 a, b$ is an example of a vegetated island where the 372 secondary back channel was unambiguously part of the active channel in an image 373 from 1938 and unambiguously part of the floodplain in an image from 1975, but in the 3741954 and 1961 images, there was ambiguity in whether the surface was the channel or 375 floodplain. This interpretation uncertainty implied that the surface could be classified as 376 a vegetated island in $A_{\max }$ (Figure 6a) or as part of the floodplain in $A_{\min }$ (Figure 6b).

377 Similarly, Figure $6 \mathrm{c}, \mathrm{d}$ is an example of a vegetated bank-attached bar that was unambiguously active channel in the 1938 image and unambiguously floodplain in the 1975 image, but there was ambiguity in whether the surface was floodplain or channel in the 1954 and 1961 images. Therefore, the surface was included as part of the active 381 channel in the $A_{\max }$ delineation (Figure $6 c$ ) and part of the floodplain in the $A_{\min }$ 382 delineation (Figure 6d).

The net planform change was calculated as the amount of erosion subtracted from 384 the amount of deposition, with positive values indicating net deposition and negative 385 values indicating net erosion. The total net planform change using the SDP method, as evaluated in our case study, was calculated by overlaying the probabilistic delineations 387 in 1954 and 1961 to create a distribution of erosion and deposition polygons for each $A_{M a x}$ and $A_{M i n}$ overlay and then merging the net planform change from all $A_{M a x}$ and $A_{M i n}$ 
overlays (Figure 1 step 7 ) into a single probability distribution. This distribution represented the combined uncertainty associated with co-registration, digitization, and interpretation. We also normalized the distribution of net planform change by dividing the net areal change by the channel centerline length to facilitate interpretation and comparison among reaches. For example, if the magnitude of net change was $100 \mathrm{~m}^{2}$ of erosion and the channel length was $10 \mathrm{~m}$, the normalized net change would be $10 \mathrm{~m}$ of erosion for every downstream meter, which we would consider a large amount of erosion. Conversely, if this amount of areal change occurred over a channel length of $10,000 \mathrm{~m}$, the normalized net change would only be $0.1 \mathrm{~m}$ of erosion per a downstream meter, which we would consider a small amount of erosion. Additionally, normalizing the net planform change by the channel centerline length allowed us to interpret the results in terms of net changes in channel width. In case studies where multiple sets of aerial images are used, the net planform change should also be normalized by the number of years between each set of aerial images so that the magnitude of change between image pairs is comparable; this form of standardization would also aid in comparing channel change case studies from the literature.

\subsection{Comparison of the SDP method with existing methods of characterizing channel} change uncertainty

The uncertainty inherent to measurements of channel change from aerial images implies that any channel change analysis must consider the impact of these uncertainties on the results. We evaluated whether the SDP method improved upon previous methods by comparing the results from our case study when the uncertainty was quantified using the SDP method and two existing methods that used a spatially 
412 uniform image co-registration error and did not characterize the uncertainty

413 probabilistically. The first method $\left(\varepsilon_{1}\right)$ was similar to that of Urban and Rhoads (2003)

414 and Micheli and Kirchner (2002) in that we created an uncertainty bound with a width of 415 the propagated co-registration error and digitization uncertainty using:

$$
\varepsilon_{1}=\left[r m s e_{t 1}{ }^{2}+r m s e_{t 2}{ }^{2}+\varepsilon_{\text {digitizing }}{ }^{2}\right]^{0.5} ; \#(7)
$$

417 where $r m s e_{t 1}$ and $r m s e_{t 2}$ were the spatially uniform co-registration errors for each image 418 (i.e., 4.95 and $4.52 \mathrm{~m}$ for the 1954 and 1961 images, respectively) and $\mathcal{E}_{\text {digitizing }}$ was the 419 maximum digitization uncertainty, which we assumed to be $2 \mathrm{~m}$. The maximum area for 420 each erosional or depositional polygon was the area of the $\varepsilon_{1}$ uncertainty band added to 421 the original polygon (Figure $7 \mathrm{a}-\mathrm{c}$ ), and the minimum area was the $\varepsilon_{1}$ uncertainty band 422 subtracted from the original polygon (Figure $7 d-f)$. The minimum net planform change 423 was the sum of the maximum area of erosion for all polygons (Figure 7c) subtracted 424 from the sum of the minimum area of deposition (Figure 7f). The maximum net planform 425 change was the sum of the minimum area of erosion (Figure $7 f$ ) subtracted from the 426 sum of the maximum area of deposition (Figure 7c). The second method $\left(\varepsilon_{2}\right)$ was developed by Swanson et al. (2011) and involved 428 estimating uncertainty in the width of each polygon of erosion and deposition using 429 equation 7 and converting the width uncertainty to an area by multiplying by the polygon 430 length. The total magnitude of uncertainty in erosion or deposition was the sum of 431 uncertainty across all erosional or depositional polygons, and the minimum and 432 maximum bounds for net planform change were calculated in the same way as for $\varepsilon_{1}$. 
433

434

435

436

437

438

439

440

441

442

443

444

445

446

447

448

449

450

451

452

453

454

455

\subsection{Results: Comparison of methods to quantify the uncertainty associated with} channel change

The output from the SDP method was a distribution of planform change that we used to calculate the probability that net change in our case study was erosional or depositional along with a $95 \%$ credible interval as a summary metric of uncertainty. The $95 \%$ credible interval contained $95 \%$ of the most probable values and thus provided a measure of uncertainty comparable to the spatially uniform $\varepsilon_{1}$ and $\varepsilon_{2}$ methods. We suggest that the $95 \%$ credible interval could be a useful metric of uncertainty in other studies that are not necessarily focused on directly comparing uncertainty methods, as was the main objective of our case study.

The SDP method, as implemented in our case study, significantly reduced the magnitude of uncertainty in measurements of areal channel change compared to the $\varepsilon_{1}$ and $\mathcal{E}_{2}$ methods. The maximum extents of erosion and deposition using the $\mathcal{E}_{1}$ method (Figure 8a) were greater than the maximum extents using the SDP method (Figure 8c) because the $\mathcal{E}_{1}$ uncertainty bound (Equation 7 ) was generally larger than the local probabilistic delineation of the channel extent generated by the SDP method.

Conversely, the minimum extent of erosion and deposition using the $\varepsilon_{1}$ method (Figure $8 b)$ was much smaller than the SDP method (Figure $8 d$ ) because $\varepsilon_{1}$ uncertainty band was greater than the size of several polygons, which caused those polygons to be completely removed from the $\varepsilon_{1}$ minimum extent (Figure $8 b$ ). The combined effect of these differences was a reduction in the uncertainty of deposition by $72 \%$ and $78 \%$ relative to $\mathcal{E}_{1}$ and $\mathcal{E}_{2}$, respectively, and in erosion by $84 \%$ and $87 \%$ relative to $\mathcal{E}_{1}$ and $\mathcal{E}_{2}$, respectively (Figure $8 \mathrm{c}, \mathrm{d}$ inset; Table 1 ). The negative minimum bound of erosion and 
456 deposition in the $\varepsilon_{2}$ method (Table 1; inset Figure 8c,d) had no physical meaning 457 because the amount of erosion and deposition could not be less than zero. This 458 spurious result was caused by the uncertainty being greater than the planform change 459 (e.g., $A_{\operatorname{Max}(t 1)} \& A_{\operatorname{Min}(2)}$ deposition was $6.5 \pm 14.0$; Table 1). In our case study, we could not conclude with confidence whether the channel 461 margins or vegetated islands accumulated or evacuated sediment, nor the direction of 462 the total net planform change, using the $\varepsilon_{1}$ and $\varepsilon_{2}$ methods, because the uncertainty 463 band spanned zero (Figure 9). Although the SDP 95\% credible interval also spanned 464 zero, the results were more informative, because we could estimate the probability of 465 change. More specifically, we found a $37 \%$ probability that the total net planform change 466 was depositional (Figure 9a; Table 1), a 19\% probability that the channel boundary 467 accumulated sediment (Figure 9b; Table 1), and a 100\% probability that vegetated 468 islands accumulated sediment (Figure 9c; Table 1). Also, the magnitude of the $95 \%$ credible interval associated with the distribution generated by the SDP method was $80 \%$ 470 and $78 \%$ smaller than the $\mathcal{E}_{1}$ and $\mathcal{E}_{2}$ uncertainty bounds, respectively (Table 1 ). Thus, 471 the SDP method significantly reduced the bound of uncertainty compared to the $\mathcal{E}_{1}$ and $472 \quad \varepsilon_{2}$ methods. The distribution of change generated from the SDP method provided a 474 quantitative basis for deciding whether the probability of change in our case study was 475 large enough to support meaningful geomorphic conclusions. For the purposes of this 476 case study, there was an inconsequential risk associated with accepting the channel 477 change results as true change when the change might have been caused by co478 registration error or digitization and interpretation uncertainty, so we decided that a $19 \%$ 
479 probability of deposition along the channel boundary was sufficient to justify the 480 conclusion that the channel boundary evacuated sediment. Similarly, we concluded 481 that the vegetated islands accumulated sediment based on a $100 \%$ probability of 482 vegetated island deposition. Overall, the net channel change was erosional rather than 483 depositional based on a $37 \%$ probability that the net change was depositional.

484 Conversely, the only conclusion that could be made for our case study based on the $\varepsilon_{1}$ 485 and $\mathcal{E}_{2}$ method was that the results implied an indeterminate net sediment balance.

\subsubsection{The relative magnitude of each type of error and uncertainty}

The SDP method processes each source of error and uncertainty individually, which avoids the requirement that errors and uncertainties be normally distributed with a mean of zero for error propagation. This is an important improvement to the $\varepsilon_{1}$ and $\varepsilon_{2}$ methods that incorrectly assume that the RMSE has a mean error of zero. Additionally, processing uncertainties individually allowed us to assess the net effect of each type of uncertainty on channel change to identify the primary driver of uncertainty in our case study. Such an analysis could not have been performed using traditional methods that rely on error propagation.

The magnitude of the co-registration error in our case study was defined by extracting $\left\|\rightarrow \vec{\varepsilon}_{x y}\right\|$ from each $A_{\max }$ and $A_{\min }$ vertex for the 10 error surfaces. The magnitude 497 of the digitization uncertainty was simply the normal distribution defined in Section 3.1 as having a mean of zero and a standard deviation of $2 / 3$. Interpretation uncertainty was

499 calculated as the difference between the minimum and maximum active channel areas 500 in our study reach calculated within 150 channel-spanning cells spaced at $150-\mathrm{m}$ 
501 streamwise intervals along the channel centerline. The difference in area within each

502 cell was normalized by the channel centerline length, which allowed us to express the 503 interpretation uncertainty in units of length comparable to the co-registration error and 504 digitization uncertainty.

In our case study, co-registration was the largest source of error, followed by

506 interpretation and digitization uncertainty (Figure 10). The median of the image co-

507 registration error was larger than the interpretation uncertainty ( 3.0 vs. $0.0 \mathrm{~m}$ ), but the

508 mean was comparable ( 3.7 vs. $3.3 \mathrm{~m}$ ). By definition, the mean of the digitization

509 uncertainty was $0 \mathrm{~m}$ and smaller than interpretation uncertainty and co-registration

510 error. The median of the interpretation uncertainty was extremely small because in $56 \%$

511 of the study area the extent of the channel boundary was unambiguous. Conversely, the

512 co-registration error was greater than zero throughout the entire study area. If we only

513 considered cells where the interpretation uncertainty was greater than $0 \mathrm{~m}$, the median

514 interpretation uncertainty increased to $2.4 \mathrm{~m}$ and the mean increased to $7.4 \mathrm{~m}$. The

515 results of our case study suggest that interpretation uncertainty can be much larger than

516 any other source of uncertainty, implying that interpretation uncertainty should be

517 considered in all studies of channel change. However, we emphasize that the results

518 presented here are unique to our case study and that the magnitude of each source of

519 uncertainty could be different in other studies.

\subsubsection{Net effect of interpretation uncertainty}

521 The overall effect of interpretation uncertainty in our case study was

522 characterized by individually examining the net change in different $A_{\max }$ and $A_{\min }$

523 overlays and we found that different $A_{\max }$ and $A_{\min }$ overlays tended toward net erosion 
524 or deposition (Figure 11). The difference was greatest when $A_{\operatorname{Min}}$ and $A_{\text {Max }}$ were

525 overlaid: $A_{\operatorname{Max}(11)} \& A_{\operatorname{Min}(t 2)}$ had a $90 \%$ probability of net deposition whereas $A_{\operatorname{Min}(11)} \& A_{\operatorname{Max}(t 2)}$

526 only had a $1 \%$ probability of net deposition (Figure 11a,b; Table 1). We attributed this

527 result to the $A_{\operatorname{Max}(11)} \& A_{\operatorname{Min}(2)}$ overlay favoring net deposition along the channel margins

528 and vegetated islands (Figure 12), which created a high probability that the net planform

529 change was depositional (Figure 11a). The magnitude of vegetated island deposition

530 was smaller for the $A_{\operatorname{Min}(11)} \& A_{\operatorname{Max}(12)}$ overlay (Figure 12a) and sediment was evacuated

531 from the channel margin (Figure 12b), decreasing the probability that net planform

532 change was depositional for the $A_{\operatorname{Min}(11)} \& A_{\operatorname{Max}(t 2)}$ overlay (Figure 11b). The net planform

533 change along the channel margins and vegetated islands differed little between the

$534 A_{\operatorname{Max}(11)} \& A_{\operatorname{Max}(12)}$ and $A_{\operatorname{Min}(11)} \& A_{\operatorname{Min}(t 2)}$ overlays (Figure 12), and the probability that each

535 overlay was depositional was similar (Figure $11 \mathrm{c}, \mathrm{d})$. Thus, the $\mathrm{A}_{\operatorname{Max}(11)} \& \mathrm{~A}_{\operatorname{Max}(\mathrm{t} 2)}$ and

$536 A_{\operatorname{Min}(11)} \& A_{\operatorname{Min}(12)}$ overlays represented the most conservative amount of channel change

537 and the probability of this scenario occurring in the overall distribution of net change

538 was $50 \%$. Conversely, the $A_{\operatorname{Min}(11)} \& A_{\operatorname{Max}(12)}$ and $A_{\operatorname{Max}(11)} \& A_{\operatorname{Min}(2)}$ overlays represented the

539 most extreme amount of deposition or erosion and each of these scenarios had a $25 \%$

540 chance of occurring in the overall distribution of net change.

541 4. Discussion

Numerous studies have analyzed repeat aerial images to detect channel change,

543 but the lack of a consistent methodology to quantify and incorporate uncertainty has led

544 to the use of many methods for estimating uncertainty in measurements of channel

545 change with varying degrees of rigor and complexity (Gurnell et al., 1994; Winterbottom

546 and Gilvear, 1997; Mount et al., 2003; Mount and Louis, 2005). Previous methods to 
547 quantify uncertainty could only be applied to one type of channel change measurement

548 (i.e., linear channel adjustments or polygons of change), which prevents these methods

549 from being applicable to all channel change studies. The SDP method presented here is

550 the first generalizable method for characterizing uncertainty associated with

551 measurements of channel change that can be used with all forms (i.e., both linear and

552 areal metrics) of channel change measurements from an image time series.

The SDP method improves upon other methods of quantifying uncertainties by

554 estimating planform change probabilistically, rather than specifying a LoD threshold and

555 discarding measured changes less than this threshold (Winterbottom and Gilvear, 1997;

556 Martin, 2003; Urban and Rhoads, 2003; Surian et al., 2009; White et al., 2010; De Rose

557 and Basher, 2011; Kessler et al., 2013). By avoiding the use of a LoD threshold, the

558 SDP method retains all polygons of channel change and calculates a distribution of

559 each polygon's area given the uncertainty. The retention of all channel change

560 measurements is a significant improvement to previous methods that discard changes

561 smaller than a threshold because all polygons of change, whether small or large,

562 contribute to our understanding of the processes and mechanisms by which channels

563 adjust. Additionally, eliminating the LoD threshold has the potential to significantly

564 improve the accuracy of channel change studies that use bank line retreat to estimate

565 volumes of bank erosion (Rhoades et al., 2009; De Rose and Basher, 2011; Day et al.,

566 2013; Kessler et al., 2013), because point bars are commonly constructed to a lower

567 elevation than eroding cutbanks (Lauer and Parker, 2008) and slivers of bank retreat

568 removed by the LoD threshold can sum to large volumes of erosion when they extend

569 over a large area and are multiplied by the bank height. 
The case study presented in this paper demonstrated that the SDP method can

571 significantly reduce the uncertainty in measurements of channel change from repeat

572 aerial images. While the SDP method is rigorous and robust, the technique is

573 computationally intensive. For example, in our case study we sampled our probabilistic

574 distributions 5,000 times to create a distribution of 20,000 channel change

575 measurements and the runtime for this analysis was $\sim 20$ minutes on a computer with 32

576 gigabytes of RAM and a $3.70 \mathrm{GHz}$ processor. In comparison, the runtime for the $\mathcal{E}_{1}$ and

$577 \mathcal{E}_{2}$ methods was less than 1 minute.

One way to decrease the SDP processing time is to reduce the number of randomly

579 sampled channel boundary delineations used to calculate the distribution of channel

580 change measurements (Figure 1 step 6). To test the sensitivity of the distribution of

581 channel change to sample size, we ran the SDP method using a range of sample sizes

582 from 1,000 to 10,000 . This sensitivity analysis showed that the distributions of channel

583 change measurements were similar for all sample sizes (Figure 13), implying that we

584 could have reduced the number of samples to 1,000 without significantly changing our

585 results. If computation time is a concern in other studies, we suggest performing a

586 similar sensitivity analysis on a subset of the study area to determine the optimal

587 number of sampled boundary delineations used to create the distribution of channel

588 change.

589 4.1. When to use the SDP method

$590 \quad$ Not all channel change studies require a method as rigorous and robust as the SDP 591 method to quantify uncertainty. We suggest that the level of complexity and rigor

592 appropriate for any effort to detect channel change depends on three factors: the 
593 magnitude of uncertainty compared to the magnitude of channel change, the objective 594 of the study, and the amount of time between the aerial images used to detect change.

595 In small rivers, the uncertainty can be a large proportion of the total channel area 596 (Swanson et al., 2011) and channel change may need to be quite large (e.g., greater 597 than $25 \%$ of the width of the channel) compared to the size of the river to overcome the 598 geospatial uncertainty. In such instances, the smaller bound of uncertainty produced by 599 the SDP method will increase the likelihood of detecting channel change. When the 600 signal of channel change is extremely large, as in laterally unstable rivers, a less 601 complex uncertainty characterization method might be suitable regardless of the 602 channel size (e.g., Surian, 1999; Cadol et al., 2011; Ziliani and Surian, 2012; Moretto et 603 al., 2014; Righini et al., 2017).

We identified two sites of bank erosion from our channel change case study where 605 channel change was large enough that a less robust uncertainty method could be used and where channel change was small and only detectable by the SDP method. Bank 607 erosion at both sites was visible by comparing the 1954 to 1961 aerial images but the $\mathcal{E}_{1}$ 608 and $\varepsilon_{2}$ methods produced an indeterminate result when the magnitude of erosion was 609 small, whereas the SDP method could detect this small erosional signal (Figure 14a,b).

610 Conversely, the $\varepsilon_{1}, \varepsilon_{2}$, and SPD methods could all detect bank erosion when the signal 611 was large (Figure 14c,d). This example from our case study highlights the benefit of 612 using the SDP method when the signal of channel change is small compared to the 613 uncertainty.

614 When the study objective is to calculate the absolute magnitude of planform change, 615 rather than the direction of change as erosional or depositional, the SDP method 
616

617

618

619

620

621

622

623

624

625

626

significantly reduces the uncertainty bound (Table 1) and enables a more precise estimate of the magnitude of channel change. We demonstrate this capability using the two sites of bank erosion from our channel change case study discussed above (Figure 14). The $\varepsilon_{1}$ and $\varepsilon_{2}$ methods predicted anywhere from $0.65 \mathrm{~m}$ of deposition to $15 \mathrm{~m}$ of erosion at the site with a smaller amount of bank erosion, whereas the SDP method predicted 3.5 to $8 \mathrm{~m}$ of bank erosion (Figure 14a,b). At the site with a larger amount of bank erosion, there was anywhere from 2 to $28 \mathrm{~m}$ of erosion using the $\varepsilon_{1}$ and $\varepsilon_{2}$ methods but that uncertainty bound was reduced to 13 to $18 \mathrm{~m}$ of erosion using the SDP method (Figure 14c,d). These examples demonstrate how well the SDP method can constrain the magnitude of channel change, and we suggest that this method be used when the study objective is to calculate the absolute magnitude of change.

Lastly, the temporal interval between aerial images compared to the activity of the channel during that interval will govern the amount of channel change recorded and, therefore, the type of uncertainty analysis needed to detect significant channel change. When aerial images are acquired in closely spaced time intervals and channel change is small (e.g., Manners et al., 2014), the SDP method might facilitate channel change detection. Conversely, when channel changes are large, significant channel change might be detectable with a less robust form of uncertainty analysis, regardless of the time interval between aerial images.

\subsection{When does each type of error and uncertainty matter?}

In the SDP method, we distinguish between error and uncertainty by defining error as a deviation from a known value and uncertainty as a range of values that encompasses the true measurement. One advantage of the SDP method is that errors 
639 and uncertainties are added individually rather than being propagated to a single value, 640 and by doing so, the user can evaluate the relative magnitude of each source of error and uncertainty and assess the effects on the channel change analysis. In our case 642 study, co-registration error was the greatest source of error, followed by interpretation and digitization uncertainty (Figure 10), but the significance of each type of uncertainty

644 might be different in other study areas, or within the same study area when using 645 different aerial images. In the following sections, we describe scenarios when each source of uncertainty is significant and other scenarios when that type of uncertainty might be disregarded. Understanding which sources of uncertainty are important in a given study can help guide the selection of an appropriate uncertainty method.

\subsubsection{Spatially distributed image co-registration error} planform change. When planform metrics are derived from a single image (e.g., width 652 and active channel area), the co-registration error is irrelevant, because the images are 653 not overlaid, although image distortion can still cause uncertainty in these planform 654 metrics if the images are not orthorectified. The co-registration error can be quantified 655 as uniform across the study area using the RMSE (Equation 5) of tie-points used to 656 warp the image, the RMSE (Equation 5) of independent test-points, or the co-

657 registration error can be allowed to vary spatially, as done in the SDP method (Figure 1 658 step1). When planform change is small (e.g., less than $25 \%$ of the width of the channel), 659 a spatially variable co-registration error is necessary, because this error is often lower 660 than the uniform RMSE near the channel, which allows smaller planform changes to be 661 detected. In our case study, using a spatially variable co-registration error reduced the 
662 error at $\sim 83 \%$ of the $A_{\min }$ and $A_{\max }$ vertices in the 1954 and 1961 images (Figure 15)

663 and shrunk the overall uncertainty bounds by $78-90 \%$ (Table 1 ). If the planform change

664 is extremely large, the uniform RMSE might be small compared to the channel change

665 signal and a spatially variable co-registration error would not be necessary. To decide

666 whether the co-registration error should be allowed to vary spatially, the magnitude of

667 uncertainty in the $\varepsilon_{1}$ method can be compared to estimated planform change when

668 uncertainty is not considered. If the $\varepsilon_{1}$ uncertainty bound is greater than the magnitude

669 of change, co-registration error should be allowed to vary spatially.

670 The effectiveness of the spatially variable co-registration error in reducing

671 uncertainty will depend on the number, distribution, and quality of test-points. We

672 suggest using an automated procedure to generate test-points throughout the study

673 area (e.g., Carbonneau et al., 2010) and supplementing those test-points with manually

674 selected test-points near the channel. Additionally, the user could test the sensitivity of

675 the SDP method to the number, density, and distribution of test-points in their study

676 area.

677

\subsubsection{Digitization uncertainty}

Digitization uncertainty is affected by the spatial and spectral resolution of the image.

679 The spatial resolution determines the smallest object that can be observed in an image.

680 The appropriate spatial resolution for a channel change analysis will depend on the

681 channel dimensions and might vary within the study area. If the spatial resolution is low

682 and the channel is narrow, a single pixel may contain a portion of the active channel

683 and the channel boundary, introducing uncertainty as to where to place the boundary

684 within the pixel. The greater the proportion of pixels that contain both the active channel 
685 and the channel boundary, the larger the digitization uncertainty. Spectral resolution 686 refers to the range of wavelengths within each one of the sensor's spectral bands. Aerial images collected by sensors with a high spectral resolution are more likely to 688 have a near-infrared wavelength band. This type of band is helpful, because the nearinfrared wavelength can be used to distinguish the boundary between vegetation, water, and bare channel bars, which reduces the digitization uncertainty.

The crispness of the boundary can also affect digitizing uncertainty. Easily identifiable features with sharp boundaries, like roads or buildings, will have a smaller digitizing uncertainty than fuzzy boundaries that are less crisp, such as trees. Along 694 rivers in arid regions with little vegetation, actively eroding banks create crisp 695 boundaries and have low digitizing uncertainty. In humid or mountainous regions, vegetation along the channel boundary is denser and eroding banks cause trees to fall

697 into the channel, making the boundary fuzzier and subject to larger digitizing uncertainty. Shadows can cause crisp boundaries to become fuzzy during certain times of the day; digitization uncertainty is thus sensitive to flight timing.

Most study areas contain both crisp and fuzzy boundaries, which will cause the 701 digitizing uncertainty to vary spatially. Currently, a spatially variable digitizing uncertainty has not been used in a channel change study; this is an area for future work. Although 703 the SDP method does not directly incorporate a spatially variable digitizing uncertainty, 704 the distribution used to describe the digitizing uncertainty can be adjusted to account for 705 fuzzy and crisp boundaries by increasing the standard deviation or creating a mixed 706 normal distribution. In this way, the SDP method is a significant improvement to 707 previous methods that use a single value to define digitizing uncertainty. 


\subsubsection{Interpretation uncertainty}

Interpretation uncertainty occurs when there are different plausible interpretations of the extent of the active channel. If the channel boundary can be identified based on breaks in topography from stereo images or digital elevation models, the interpretation uncertainty will tend to be smaller. However, freely available aerial images that are regularly acquired typically are not collected in stereo, and current practice involves delineating channel boundaries in GIS software without the aid of stereo images.

In our case study, interpretation uncertainty was a large source of uncertainty in some localized areas, but there was no uncertainty elsewhere. This caused the median of this uncertainty to be small (Figure $10 ; 0.00 \mathrm{~m}$ ), because the uncertainty was not present in $56 \%$ of the study area. In other case studies, interpretation uncertainty might be small in localized areas or more pervasive throughout the study area. We suspect that interpretation uncertainty will be high in rivers that experience a large change in wetted channel area given a proportionately small change in discharge (e.g., braided rivers), because low-elevation bars are frequently wetted but not scoured, which allows fast-growing vegetation to encroach on these surfaces (Werbylo et al., 2017). In such rivers, vegetation density is a poor proxy for the active channel, and the digitizer must use professional judgment in placing the active channel boundary. Similarly, vegetation might be a poor indication of the channel extent in rivers that experience flashy hydrology or that are subjected to large reset floods and very low base flows, because there might be a mosaic of bare alluvial surfaces at multiple elevations after a large flood that are hard to interpret (Dean and Schmidt, 2011, 2013; Thompson and Croke, 
2013). Additionally, in humid environments where plants grow quickly, vegetation growing in the active channel during base flow can introduce ambiguity.

Interpretation uncertainty is likely to be larger for channels that are narrowing as compared to those that are widening. Channels widen through bank erosion that removes an entire section of sediment and creates an abrupt, crisp contact between the channel and floodplain with minimal interpretation uncertainty. Conversely, channel narrowing occurs over a continuum as alluvial surfaces transition from active channel bars to floodplains by vertically aggrading sediment (Allred and Schmidt, 1999; Grams and Schmidt, 2002; Moody et al., 1999; Pizzuto, 1994). Determining when enough sediment has accumulated on an alluvial surface to form a stable floodplain that is inundated by floods of an annual or greater recurrence is highly uncertain and subject to large interpretation uncertainty.

\section{Conclusions}

In this paper, we introduced a new method for quantifying uncertainty associated with channel change detection based on probabilistic, spatially varying estimates of coregistration error and digitization uncertainty. We also presented a framework that can be used to incorporate interpretation uncertainty into the channel change analysis. The SDP method can be used to calculate uncertainty at specific locations of linear channel adjustment or polygons of erosion and deposition, while also estimating the central tendency of net planform change, making this the first generalizable method for quantifying uncertainty that can be applied to all metrics of channel change derived from aerial image overlays. Although the focus of this paper was the detection of channel change, the SDP method can be applied to other geomorphic and landscape change 
753 detection analyses, such as glacial change (DeVisser and Fountain, 2015), shoreline or

754 tidal wetland change (Del Río et al., 2013), and changes in water body surfaces

755 (Necsoiu et al., 2013).

756

757

758

759

760

761

762

763

764 765 indeterminate.

The SDP method as applied to our case study reduced the magnitude of uncertainty by $83-87 \%$ compared to two existing methods that used a spatially uniform image co-registration error and did not characterize uncertainty probabilistically. By reducing the bounds of uncertainty, we were able to detect channel changes of a smaller magnitude. More importantly, the distribution information from the SDP method allowed us to report a magnitude of channel change in our case study with an appropriate level of confidence even though the uncertainty bound included zero. We could not make a similar inference using the existing methods, because their uncertainty bounds had no distribution information and included zero, making the results

The SDP method was an improvement to existing methods that quantify uncertainty without distributional information, but the method was computationally intensive and might not be necessary for all change detection studies. We suggest that the SDP method should be used in channel change studies where 1) the uncertainty is a large proportion of the total channel area, as in small rivers; 2) when the temporal spacing between aerial images is short and the channel change is expected to be small; and 3) when the purpose of the study is to calculate the absolute magnitude of change, such as studies that use bank retreat to calculate the volume of bank erosion.

\section{Acknowledgments}


775 The work by the first author was supported by the Colorado River Doctoral Scholar 776 program of the Center for Colorado River Studies at Utah State University and by the 777 Babbitt Center for Land and Water Policy. Any use of trade, firm, or product names is 778 for descriptive purposes only and does not imply endorsement by the U.S. Government.

\section{Data Availability}

780 A MATLAB $®$ script for performing an SDP uncertainty analysis is available at 781 https://qcnr.usu.edu/coloradoriver/files/leonard_data. The data used in this case study 782 are available from the U.S. Geological Survey (USGS) ScienceBase at

783 https://doi.org/10.5066/P9SEBJ3X (Legleiter and Leonard, 2020). 


\section{References}

Agisoft LLC. 2016. Agisoft Photoscan Professional edition

Allred TM, Schmidt JC. 1999. Channel narrowing by vertical accretion along the Green River near Green River, Utah. GSA Bulletin 111 : 1757-1772. DOI: 10.1130/00167606(1999)111<1757:CNBVAA>2.3.CO;2

Amidror I. 2002. Scattered Data Interpolation Methods for Electronic Imaging Systems: A Survey. Journal of Electronic Imaging 11 : 157-176. DOI: 10.1117/1.1455013

Anderson S, Pitlick J. 2014. Using repeat LiDAR to estimate sediment transport in a steep stream. Journal of Geophysical Research: Earth Surface 119 : 621-643. DOI: 10.1002/2013JF002933

Anderson SW. 2019. Uncertainty in quantitative analyses of topographic change: error propagation and the role of thresholding. Earth Surface Processes and Landforms 44 : 10151033. DOI: $10.1002 /$ esp. 4551

Andrews E. 1980. Effective and bankfull discharges of streams in the Yampa River basin, Colorado and Wyoming. Journal of Hydrology 46 : 311-330. DOI: 10.1016/00221694(80)90084-0

Best J. 2019. Anthropogenic stresses on the world's big rivers. Nature Geoscience 12 : 7-21. DOI: $10.1038 / s 41561-018-0262-x$

Bollati IM, Pellegrini L, Rinaldi M, Duci G, Pelfini M. 2014. Reach-scale morphological adjustments and stages of channel evolution: The case of the Trebbia River (northern Italy). Geomorphology 221 : 176-186. DOI: 10.1016/j.geomorph.2014.06.007

Brasington J, Langham J, Rumsby B. 2003. Methodological sensitivity of morphometric estimates of coarse fluvial sediment transport. Geomorphology $53: 299-316$. DOI: 10.1016/S0169-555X(02)00320-3

Buckingham SE, Whitney JW. 2007. GIS Methodology for Quantifying Channel Change in Las Vegas, Nevada. JAWRA Journal of the American Water Resources Association 43 : 888-898. DOI: 10.1111/j.1752-1688.2007.00073.x

Cadol D, Rathburn SL, Cooper DJ. 2011. Aerial photographic analysis of channel narrowing and vegetation expansion in Canyon De Chelly National Monument, Arizona, USA, 1935-2004. River Research and Applications 27 : 841-856. DOI: 10.1002/rra.1399

Carbonneau PE, Dugdale SJ, Clough S. 2010. An automated georeferencing tool for watershed scale fluvial remote sensing. River Research and Applications 26 : 650-658. DOI: 10.1002/rra.1263

Comiti F, Da Canal M, Surian N, Mao L, Picco L, Lenzi MA. 2011. Channel adjustments and vegetation cover dynamics in a large gravel bed river over the last 200 years. Geomorphology 125 : 147-159. DOI: 10.1016/j.geomorph.2010.09.011 
820 Day SS, Gran KB, Belmont P, Wawrzyniec T. 2013. Measuring bluff erosion part 2: pairing

821

822

823

824

825

826

827

828

829

830

831

832

833

834

835

836

837

838

839

840

841

842

843

844

845

846

847

848

849

850

851

852

853

854

855

856 aerial photographs and terrestrial laser scanning to create a watershed scale sediment budget. Earth Surface Processes and Landforms 38 : 1068-1082. DOI: 10.1002/esp.3359

De Rose RC, Basher LR. 2011. Measurement of river bank and cliff erosion from sequential LIDAR and historical aerial photography. Geomorphology 126 : 132-147. DOI:

10.1016/j.geomorph.2010.10.037

Dean DJ, Schmidt JC. 2011. The role of feedback mechanisms in historic channel changes of the lower Rio Grande in the Big Bend region. Geomorphology 126 : 333-349. DOI:

10.1016/j.geomorph.2010.03.009

Dean DJ, Schmidt JC. 2013. The geomorphic effectiveness of a large flood on the Rio Grande in the Big Bend region: Insights on geomorphic controls and post-flood geomorphic response. Geomorphology 201 : 183-198. DOI: 10.1016/j.geomorph.2013.06.020

Del Río L, Gracia FJ, Benavente J. 2013. Shoreline change patterns in sandy coasts. A case study in SW Spain. Geomorphology 196 : 252-266. DOI: 10.1016/j.geomorph.2012.07.027

DeVisser MH, Fountain AG. 2015. A century of glacier change in the Wind River Range, WY. Geomorphology 232 : 103-116. DOI: 10.1016/j.geomorph.2014.10.017

Donovan M, Belmont P. 2019. Timescale dependence in river channel migration measurements. Earth Surface Processes and Landforms 44 : 1530-1541. DOI: 10.1002/esp.4590

Donovan M, Belmont P, Notebaert B, Coombs T, Larson P, Souffront M. 2019. Accounting for uncertainty in remotely-sensed measurements of river planform change. Earth-Science Reviews 193 : 220-236. DOI: 10.1016/j.earscirev.2019.04.009

Downward SR, Gurnell AM, Brookes A. 1994. A methodology for quantifying river channel planform change using GIS. IAHS Publications-Series of Proceedings and Reports-Intern Assoc Hydrological Sciences 224 : 449-456.

Gaeuman D, Symanzik J, Schmidt JC. 2005. A map overlay error model based on boundary geometry. Geographical Analysis 37 : 350-369. DOI: 10.1111/j.1538-4632.2005.00585.x

Gaeuman DA, Schmidt JC, Wilcock PR. 2003. Evaluation of in-channel gravel storage with morphology-based gravel budgets developed from planimetric data. Journal of Geophysical Research: Earth Surface 108 : 6001. DOI: 10.1029/2002JF000002

Grams PE, Schmidt JC. 2002. Streamflow regulation and multi-level flood plain formation: channel narrowing on the aggrading Green River in the eastern Uinta Mountains, Colorado and Utah. Geomorphology 44 : 337-360. DOI: 10.1016/S0169-555X(01)00182-9

Grams PE, Schmidt JC. 2005. Equilibrium or indeterminate? Where sediment budgets fail: Sediment mass balance and adjustment of channel form, Green River downstream from Flaming Gorge Dam, Utah and Colorado. Geomorphology 71 : 156-181. DOI: 10.1016/j.geomorph.2004.10.012 
857

858

859

860

861

862

863

864

865

866

867

868

869

870

871

872

873

874

875

876

877

878

879

880

881

882

883

884

885

886

887

888

889

890

891

892

893

Gurnell AM, Downward SR, Jones R. 1994. Channel planform change on the River Dee meanders, 1876-1992. Regulated Rivers: Research \& Management 9 : 187-204. DOI: 10.1002/rrr.3450090402

Ham DG, Church M. 2000. Bed-material transport estimated from channel morphodynamics: Chilliwack River, British Columbia. Earth Surface Processes and Landforms 25 : 1123-1142. DOI: 10.1002/1096-9837(200009)25:10<1123::AID-ESP122>3.0.CO;2-9

Hughes ML, McDowell PF, Marcus WA. 2006. Accuracy assessment of georectified aerial photographs: implications for measuring lateral channel movement in a GIS. Geomorphology 74 : 1-16. DOI: 10.1016/j.geomorph.2005.07.001

Kessler AC, Gupta SC, Brown MK. 2013. Assessment of river bank erosion in Southern Minnesota rivers post European settlement. Geomorphology 201 : 312-322. DOI:

10.1016/j.geomorph.2013.07.006

Lauer JW, Parker G. 2008. Net local removal of floodplain sediment by river meander migration. Geomorphology 96 : 123-149. DOI: 10.1016/j.geomorph.2007.08.003

Lea DM, Legleiter CJ. 2016. Refining measurements of lateral channel movement from image time series by quantifying spatial variations in registration error. Geomorphology 258 : 11-20. DOI: 10.1016/j.geomorph.2016.01.009

Legleiter CJ. 2014. Downstream Effects of Recent Reservoir Development on the Morphodynamics of a Meandering Channel: Savery Creek, Wyoming, Usa. River Research and Applications : 1328-1343. DOI: 10.1002/rra.2824

Legleiter CJ, Leonard CM. 2020. Aerial photographs from the Yampa and Little Snake Rivers in northwest Colorado used to characterize channel changes occuring between 1954 and 1961. U.S. Geological Survey data release [online] Available from: https://doi.org/10.5066/P9SEBJ3X

Leonard C, Legleiter C, Overstreet B. 2017. Effects of lateral confinement in natural and leveed reaches of a gravel-bed river: Snake River, Wyoming, USA. Earth Surface Processes and Landforms 42 : 2119-2138. DOI: 10.1002/esp.4157

Lyons JK, Pucherelli MJ, Clark RC. 1992. Sediment transport and channel characteristics of a sand-bed portion of the Green River below Flaming Gorge Dam, Utah, USA. Regulated Rivers: Research \& Management 7 : 219-232. DOI: 10.1002/rrr.3450070302

Magilligan FJ, Haynie HJ, Nislow KH. 2008. Channel Adjustments to Dams in the Connecticut River Basin: Implications for Forested Mesic Watersheds. Annals of the Association of American Geographers 98 : 267-284. DOI: 10.1080/00045600801944160

Manners RB, Schmidt JC, Scott ML. 2014. Mechanisms of vegetation-induced channel narrowing of an unregulated canyon river: Results from a natural field-scale experiment. Geomorphology 211 : 100-115. DOI: 10.1016/j.geomorph.2013.12.033

Martin DJ, Pavlowsky RT. 2011. Spatial Patterns of Channel Instability Along an Ozark River, Southwest Missouri. Physical Geography 32 : 445-468. DOI: 10.2747/0272-3646.32.5.445 
894 895

896

897

898

899

900

901

902

903

904

905

906

907

908

909

910

911

912

913

914

915

916

917

918

919

920

921

922

923

924

925

926

927

928

929

Martin Y. 2003. Evaluation of bed load transport formulae using field evidence from the Vedder River, British Columbia. Geomorphology 53 : 75-95. DOI: 10.1016/S0169-555X(02)00348-3

Merritt DM, Cooper DJ. 2000. Riparian vegetation and channel change in response to river regulation: a comparative study of regulated and unregulated streams in the Green River Basin, USA. Regulated Rivers: Research \& Management 16 : 543-564. DOI: 10.1002/10991646(200011/12)16:6<543::AID-RRR590>3.0.CO;2-N

Micheli ER, Kirchner JW. 2002. Effects of wet meadow riparian vegetation on streambank erosion. 1. Remote sensing measurements of streambank migration and erodibility. Earth Surface Processes and Landforms 27 : 627-639. DOI: 10.1002/esp.338

Moody JA, Pizzuto JE, Meade RH. 1999. Ontogeny of a flood plain. GSA Bulletin 111 : $291-$ 303. DOI: 10.1130/0016-7606(1999)111<0291:OOAFP>2.3.CO;2

Moretto J, Rigon E, Mao L, Picco L, Delai F, Lenzi MA. 2014. Channel Adjustments and Island Dynamics in the Brenta River (Italy) Over the Last 30 Years. River Research and Applications 30 : 719-732. DOI: 10.1002/rra.2676

Mount N, Louis J. 2005. Estimation and propagation of error in measurements of river channel movement from aerial imagery. Earth Surface Processes and Landforms 30 : 635-643. DOI: 10.1002/esp.1172

Mount NJ, Louis J, Teeuw RM, Zukowskyj PM, Stott T. 2003. Estimation of error in bankfull width comparisons from temporally sequenced raw and corrected aerial photographs.

Geomorphology 56 : 65-77. DOI: 10.1016/S0169-555X(03)00046-1

Nanson GC, Hickin EJ. 1983. Channel migration and incision on the Beatton River. Journal of Hydraulic Engineering 109 : 327-337.

Nardi L, Rinaldi M. 2015. Spatio-temporal patterns of channel changes in response to a major flood event: the case of the Magra River (central-northern Italy). Earth Surface Processes and Landforms 40 : 326-339. DOI: 10.1002/esp.3636

Necsoiu M, Dinwiddie CL, Walter GR, Larsen A, Stothoff SA. 2013. Multi-temporal image analysis of historical aerial photographs and recent satellite imagery reveals evolution of water body surface area and polygonal terrain morphology in Kobuk Valley National Park, Alaska. Environmental Research Letters 8 : 025007. DOI: 10.1088/1748-9326/8/2/025007

Nelson NC, Erwin SO, Schmidt JC. 2013. Spatial and temporal patterns in channel change on the Snake River downstream from Jackson Lake dam, Wyoming. Geomorphology 200 : 132142. DOI: 10.1016/j.geomorph.2013.03.019

Nilsson C, Reidy CA, Dynesius M, Revenga C. 2005. Fragmentation and Flow Regulation of the World's Large River Systems. Science 308 : 405-408. DOI: 10.1126/science.1107887

Pizzuto JE. 1994. Channel adjustments to changing discharges, Powder River, Montana. GSA Bulletin 106 : 1494-1501. DOI: 10.1130/0016-7606(1994)106<1494:CATCDP>2.3.CO;2 
930

931

932

933

934

935

936

937

938

939

940

941

942

943

944

945

946

947

948

949

950

951

952

953

954

955

956

957

958

959

960

961

962

963

964

965

966

967

Rhoades EL, O'Neal MA, Pizzuto JE. 2009. Quantifying bank erosion on the South River from 1937 to 2005, and its importance in assessing Hg contamination. Applied Geography 29 : 125134. DOI: 10.1016/j.apgeog.2008.08.005

Righini M, Surian N, Wohl E, Marchi L, Comiti F, Amponsah W, Borga M. 2017. Geomorphic response to an extreme flood in two Mediterranean rivers (northeastern Sardinia, Italy): Analysis of controlling factors. Geomorphology 290 : 184-199. DOI: 10.1016/j.geomorph.2017.04.014

Riquelme A, Del Soldato M, Tomás R, Cano M, Jordá Bordehore L, Moretti S. 2019. Digital landform reconstruction using old and recent open access digital aerial photos. Geomorphology 329 : 206-223. DOI: 10.1016/j.geomorph.2019.01.003

Schmidt JC, Wilcock PR. 2008. Metrics for assessing the downstream effects of dams. Water Resources Research 44 : W04404. DOI: 10.1029/2006WR005092

Schook DM, Rathburn SL, Friedman JM, Wolf JM. 2017. A 184-year record of river meander migration from tree rings, aerial imagery, and cross sections. Geomorphology 293 : 227-239. DOI: 10.1016/j.geomorph.2017.06.001

Surian N. 1999. Channel changes due to river regulation: the case of the Piave River, Italy. Earth Surface Processes and Landforms 24 : 1135-1151. DOI: 10.1002/(SICI)10969837(199911)24:12<1135::AID-ESP40>3.0.CO;2-F

Surian N, Mao L, Giacomin M, Ziliani L. 2009. Morphological effects of different channel-forming discharges in a gravel-bed river. Earth Surface Processes and Landforms 34 : 1093-1107. DOI: 10.1002/esp.1798

Swanson BJ, Meyer GA, Coonrod JE. 2011. Historical channel narrowing along the Rio Grande near Albuquerque, New Mexico in response to peak discharge reductions and engineering: magnitude and uncertainty of change from air photo measurements. Earth Surface Processes and Landforms 36 : 885-900. DOI: 10.1002/esp.2119

Thompson C, Croke J. 2013. Geomorphic effects, flood power, and channel competence of a catastrophic flood in confined and unconfined reaches of the upper Lockyer valley, southeast Queensland, Australia. Geomorphology 197 : 156-169. DOI: 10.1016/j.geomorph.2013.05.006

Topping DJ, Mueller ER, Schmidt JC, Griffiths RE, Dean DJ, Grams PE. 2018. Long-Term Evolution of Sand Transport Through a River Network: Relative Influences of a Dam Versus Natural Changes in Grain Size From Sand Waves. Journal of Geophysical Research: Earth Surface 123 : 1879-1909. DOI: 10.1029/2017JF004534

Urban MA, Rhoads BL. 2003. Catastrophic human-induced change in stream-channel planform and geometry in an agricultural watershed, Illinois, USA. Annals of the Association of American Geographers 93 : 783-796. DOI: 10.1111/j.1467-8306.2003.09304001.x

USGS. 2012. United States Geological Survey National Elevation Dataset [online] Available from: https://www.usgs.gov/core-science-systems/national-geospatial-program/national-map

USGS. 2019. United States Geological Survey Earth Explorer [online] Available from: https://earthexplorer.usgs.gov/ 
968 Wellmeyer JL, Slattery MC, Phillips JD. 2005. Quantifying downstream impacts of impoundment 969 on flow regime and channel planform, lower Trinity River, Texas. Geomorphology 69 : 1-13.

970 DOI: 10.1016/j.geomorph.2004.09.034

971 Werbylo KL, Farnsworth JM, Baasch DM, Farrell PD. 2017. Investigating the accuracy of 972 photointerpreted unvegetated channel widths in a braided river system: a Platte River case 973 study. Geomorphology 278 : 163-170. DOI: 10.1016/j.geomorph.2016.11.003

974 Wheaton JM, Brasington J, Darby SE, Sear DA. 2010. Accounting for uncertainty in DEMs from 975 repeat topographic surveys: improved sediment budgets. Earth Surface Processes and 976 Landforms 35 : 136-156. DOI: 10.1002/esp.1886

977 White JQ, Pasternack GB, Moir HJ. 2010. Valley width variation influences riffle-pool location 978 and persistence on a rapidly incising gravel-bed river. Geomorphology 121 : 206-221. DOI: 979 10.1016/j.geomorph.2010.04.012

980 Winterbottom SJ, Gilvear DJ. 1997. Quantification of channel bed morphology in gravel-bed 981 rivers using airborne multispectral imagery and aerial photography. Regulated Rivers: Research 982 \& Management 13 : 489-499. DOI: 10.1002/(SICI)1099-1646(199711/12)13:6<489::AID983 RRR471>3.0.CO;2-X

984 Winterbottom SJ, Gilvear DJ. 2000. A GIS-based approach to mapping probabilities of river 985 bank erosion: regulated River Tummel, Scotland. Regulated Rivers: Research \& Management: 986 987 An International Journal Devoted to River Research and Management 16 : 127-140. DOI: 10.1002/(SICI)1099-1646(200003/04)16:2<127::AID-RRR573>3.0.CO;2-Q

988 Ziliani L, Surian N. 2012. Evolutionary trajectory of channel morphology and controlling factors 989 in a large gravel-bed river. Geomorphology 173-174 : 104-117. DOI:

$990 \quad 10.1016 /$ j.geomorph.2012.06.001 
Table and figure captions:

993

994

995

996

997

998

999

1000

1001

1002

1003

1004

1005

1006

1007

1008

1009

1010

1011

1012

1013

1014

1015

1016

1017

1018

1019

1020

1021

1022

1023

1024

1025

1026

1027

1028

1029

1030
Table 1: Uncertainty bounds for the $\varepsilon_{1}$ and $\varepsilon_{2}$ methods and the $95 \%$ credible intervals for the SDP method. All values are normalized by the channel centerline length. Also included are the percent change between the $\varepsilon_{1}$ and SDP method ( $\left.\% \Delta S D P \varepsilon_{1}\right)$ and between the $\varepsilon_{2}$ and SDP method (\% $\left.\% \operatorname{SDP}_{\varepsilon 2}\right)$.

Figure 1: SDP algorithm flow chart.

Figure 2: Spatially distributed image co-registration error surface. (A) Image coregistration error in the $X$ direction $\left(\varepsilon_{x}\right)$. (B) Image co-registration error in the $Y$ direction $\left(\varepsilon_{y}\right)$. Positive $\varepsilon_{x}$ and $\varepsilon_{y}$ values point east and north, respectively. $\varepsilon_{x}$ and $\varepsilon_{y}$ were calculated by equations 3 and 4. (C) Resultant vectors of $\varepsilon_{\mathrm{x}}$ and $\varepsilon_{\mathrm{y}}$ calculated by equations 5 and 6.

Figure 3: Schematic showing minimum and maximum active channel delineations for interpretation uncertainty. (A) Minimum and maximum extent of the active channel and vegetated islands. These extents represent uncertainty in interpreting the channel and vegetated island boundaries. (B) Maximum area of the active channel $\left(A_{\max }\right)$ is the minimum extent of the vegetated islands subtracted from the maximum extent of the active channel. (C) Minimum area of the active channel $\left(A_{\min }\right)$ is the maximum extent of the vegetated islands subtracted from the minimum extent of the active channel.

Figure 4: Steps used to create a probabilistic boundary delineation. (A) Original boundary delineation in green and boundary delineation adjusted for co-registration error in red. The red line was created by moving each vertex of the green line by a distance of $\left\|\overrightarrow{\varepsilon_{x y}}\right\|$ in the direction $\theta$ (Figure 1c). (B) Subset of $A$. Blue lines represent the distribution of probable channel delineations around the adjusted red boundary. The distribution of blue lines was populated by randomly sampling a digitizing uncertainty from a normal distribution with a mean $(\mu)$ of zero and standard deviation $(\sigma)$ of onethird the maximum digitizing uncertainty (inset). Each vertex on the red line was moved along a normal vector with a magnitude equal to the sampled value. This was repeated 100 times. (C) Same location as B showing the full probabilistic boundary delineation. Each red line was adjusted from the original green boundary using one of the 10 coregistration error surfaces. The blue lines represent the digitization uncertainty around each of the 10 red lines.

Figure 5: Study area used to illustrate the SDP method. The study area is located in northwestern Colorado along a $17 \mathrm{~km}$ alluvial section of the Yampa River spanning the Little Snake confluence and a $7 \mathrm{~km}$ reach of the Little Snake River directly upstream from the confluence. The Deerlodge gage (USGS station \#: 09260050) is located at the downstream end of the study area. The direction of flow is from right to left. Base aerial image is from the 2017 NAIP. 
1032 Figure 6: Interpretation uncertainty characterized by minimum and maximum channel 1033 boundary delineations. (A) Partly vegetated surface on the left bank was classified as a vegetated island and a secondary channel using the $A_{\max }$ delineation. (B) Same vegetated surface as $A$ was classified as floodplain in the $A_{\min }$ delineation. (C) Vegetated bank-attached bar on the right bank was classified as active channel in the $A_{\text {max }}$ delineation. (D) Same bank-attached bar as $C$ was classified as floodplain in the $A_{\min }$ delineation. Direction of flow is from top to bottom in all images and minimum and maximum boundaries were delineated from the 1954 aerial image.

1040 Figure 7: Minimum and maximum extent of erosion and deposition was calculated by adding or subtracting a spatially uniform uncertainty bound around each polygon of erosion and deposition. Flow is from right to left and the 1954 image was used as the base image. The maximum area of erosion or deposition is the uncertainty bound added to each polygon (A, B, C) and the minimum area of erosion or deposition is the uncertainty bound subtracted from each polygon (D, E, F). The minimum bound of net planform change was the sum of erosional polygons in $C$ subtracted from the sum of depositional polygons in $\mathrm{F}$, and the maximum bound of net planform change was the sum of erosional polygons in $\mathrm{F}$ subtracted from the sum of depositional polygons in $\mathrm{C}$.

1049 Figure 8: Minimum and maximum extent of erosion and deposition using the $A_{\max (t 1)} \& A_{\max (t 2)}$ overlay. Flow is from right to left and the 1954 image was used as the base image. (A) Maximum extent of deposition and erosion using the $\varepsilon_{1}$ method. (B) Minimum extent of deposition and erosion using the $\varepsilon_{1}$ method. (C) Maximum extent of erosion and deposition using the SDP method. Inset shows the estimate for the normalized area of deposition and minimum and maximum bound of uncertainty using the $\varepsilon_{1}$ and $\varepsilon_{2}$ methods overlaid on the SDP distribution. (D) Minimum extent of erosion and deposition using the SDP method. Inset shows the estimate for the normalized area of erosion and minimum and maximum bound of uncertainty using the $\varepsilon_{1}$ and $\varepsilon_{2}$ methods overlaid on the SDP distribution. The maximum and minimum extent of erosion and deposition using the $\varepsilon_{2}$ method was not overlaid on the images because the $\varepsilon_{2}$ method calculated the magnitude of uncertainty, not the spatial extent. The SDP method reduced the magnitude of uncertainty by $72-78 \%$ for deposition and $84-87 \%$ for erosion (Table 1).

Figure 9: (A) All $A_{\max }$ and $A_{\min }$ overlay solutions merged into a single histogram fit with a probability density function which represents uncertainty in the normalized net change in area caused by co-registration, digitization, and interpretation uncertainty. The minimum and maximum bounds of uncertainty for the $\varepsilon_{1}$ and $\varepsilon_{2}$ methods are also shown. (B) Net change in A for changes that occurred along vegetated islands. 
1069 Figure 10: Box and whisker plot for each error and uncertainty type showing the median 1070 and interquartile range within the box, values $\pm 2.7 \sigma$ within the whiskers, and values < $1071 \pm 2.7 \sigma$ as outliers.

1072 Figure 11: Net planform change using each $A_{\min }$ and $A_{\max }$ overlay. Each panel shows 1073 the estimate for the normalized net change in area, the minimum and maximum bound of uncertainty using the $\varepsilon_{1}$ and $\varepsilon_{2}$ methods, and a histogram of the SDP solutions fit with a probability density function. (A) $A_{\max (11)} \& A_{\min (12)}$ overlay.

(D) $A_{\min (11)} \& A_{\min (2)}$ overlay.

1077 Figure 12: Probability density functions fit to the $A_{\min }$ and $A_{\max }$ overlay distributions 1078 partitioned by change along the channel margins and vegetated islands. (A)

1079 Normalized area of deposition along the channel margins. (B) Normalized net change 1080 along the channel margins.

Figure 13: Violin plots showing the distribution of net planform change calculated by the SDP method using 1,000 to 10,000 randomly sampled channel boundary delineations indicated by the number of bootstrap iterations. Insets show the mean and standard deviation for each violin plot.

1085

1086

1087

1088 1089
Figure 14: Example of the $\varepsilon_{1}$ and $\varepsilon_{2}$ methods and SDP method applied to two locations of bank retreat in our study area. (A) Location of small bank retreat. (B) Magnitude of channel change at the site in A calculated by the $\varepsilon_{1}$ and $\varepsilon_{2}$ methods and SDP method. (C) Location of large bank retreat. (D) Magnitude of channel change at the site in $C$ calculated by the $\varepsilon_{1}$ and $\varepsilon_{2}$ methods and SDP method.

Figure 15: Distribution of co-registration errors extracted from each vertex along the $A_{\max }$ and $A_{\min }$ boundaries in 1954 and 1961 . These data are displayed as a cumulative density function estimate and a histogram. The blue portion of these distributions have a co-registration error that is lower than the uniform RMSE and the green portion have a co-registration error that is above the uniform RMSE. $82 \%$ of the co-registration errors were above the uniform RMSE in 1954 and 84\% in 1961. 


\begin{tabular}{|c|c|c|c|c|c|}
\hline & $\varepsilon_{1}(\mathrm{~m})$ & $\varepsilon_{2}(\mathrm{~m})$ & $\mathrm{SDP}(\mathrm{m})$ & $\% \Delta \mathrm{SDP}_{\varepsilon 1}$ & $\% \Delta \mathrm{SDP}_{\varepsilon 2}$ \\
\hline \multicolumn{6}{|l|}{ Deposition } \\
\hline$A_{\operatorname{Max}(t 1)} \& A_{\operatorname{Min}(t 2)}$ & $2.6-26.9$ & $-7.6-20.5$ & $8.4-11.2$ & $89 \%$ & $90 \%$ \\
\hline$A_{\operatorname{Min}(t 1)} \& A_{\operatorname{Max}(t 2)}$ & $0.6-20.5$ & $-3.7-20.7$ & $4.12-6.7$ & $87 \%$ & $89 \%$ \\
\hline $\mathrm{A}_{\operatorname{Max}(\mathrm{t} 1)} \& \mathrm{~A}_{\operatorname{Max}(\mathrm{t} 2)}$ & $1.1-23.1$ & $-6.2-20.0$ & $5.5-8.1$ & $88 \%$ & $90 \%$ \\
\hline $\mathrm{A}_{\operatorname{Min}(11)} \& \mathrm{~A}_{\operatorname{Min}(2)}$ & $1.3-23.4$ & $-6.3-19.9$ & $5.9-8.7$ & $87 \%$ & $89 \%$ \\
\hline TOTAL & $0.6-23.4$ & $-7.6-20.7$ & $4.4-10.6$ & $72 \%$ & $78 \%$ \\
\hline \multicolumn{6}{|l|}{ Erosion } \\
\hline$A_{\operatorname{Max}(t 1)} \& A_{\operatorname{Min}(t 2)}$ & $0.4-26.4$ & $-10.5-23.4$ & $5.6-9.6$ & $85 \%$ & $88 \%$ \\
\hline$A_{\operatorname{Min}(11)} \& A_{\operatorname{Max}(t 2)}$ & $0.9-31.2$ & $-10.3-27.3$ & $7.5-11.6$ & $86 \%$ & $89 \%$ \\
\hline$A_{\operatorname{Max}(t 1)} \& A_{\operatorname{Max}(t 2)}$ & $0.4-28.8$ & $-11.6-25.4$ & $6.1-10.1$ & $86 \%$ & $89 \%$ \\
\hline $\mathrm{A}_{\operatorname{Min}(\mathrm{t} 1)} \& \mathrm{~A}_{\operatorname{Min}(\mathrm{t} 2)}$ & $0.4-27.5$ & $-10.6-24.2$ & $5.8-10.0$ & $85 \%$ & $88 \%$ \\
\hline TOTAL & $0.4-31.2$ & $-11.6-27.3$ & $5.92-10.8$ & $84 \%$ & $87 \%$ \\
\hline \multicolumn{6}{|l|}{$\Delta$ Planform Change } \\
\hline $\mathrm{A}_{\operatorname{Max}(\mathrm{t} 1)} \& \mathrm{~A}_{\operatorname{Min}(\mathrm{t} 2)}$ & $-23.8-26.6$ & $-28.7-13.8$ & $-1.1-5.5$ & $87 \%$ & $84 \%$ \\
\hline $\mathrm{A}_{\operatorname{Min}(11)} \& \mathrm{~A}_{\operatorname{Max}(\mathrm{t} 2)}$ & $-30.5-19.6$ & $-35.2-7.6$ & $-7.4-0.8$ & $87 \%$ & $84 \%$ \\
\hline $\mathrm{A}_{\operatorname{Max}(\mathrm{t} 1)} \& \mathrm{~A}_{\operatorname{Max}(\mathrm{t} 2)}$ & $-27.8-22.7$ & $-32.9-9.4$ & $-4.6-1.9$ & $87 \%$ & $85 \%$ \\
\hline $\mathrm{A}_{\operatorname{Min}(\mathrm{t} 1)} \& \mathrm{~A}_{\operatorname{Min}(\mathrm{t} 2)}$ & $-26.2-23.0$ & $-31.1-10.0$ & $-4.1-2.8$ & $83 \%$ & $83 \%$ \\
\hline TOTAL & $-27.4-26.6$ & $-35.2-13.8$ & $-6.3-4.5$ & $80 \%$ & $78 \%$ \\
\hline
\end{tabular}

Table 1 


\section{SDP Algorithm}

1) Generate co-registration error surfaces

$\checkmark$

1a) Generate independent test-points

1b) Calculate error for each test-point

1c) Withhold $10 \%$ of test-points

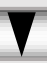

1d) Create spatially continuous $\varepsilon x$ and Ey surfaces (Figure 2)

1e) Repeat $1 c-d$ to create 10 co-registration error surfaces

3) Move each vertex of $A_{\max } \& A_{\min }$ boundaries by the magnitude and direction of the coregistration error for each of the 10 error surfaces (Figure $4 a$ )

4) Randomly sample 100 digitizing uncertainties from a normal distribution and move the adjusted boundaries in step 3 along a normal vector with a magnitude given by the sampled digitizing uncertainty (Figure $4 \mathrm{~b}$ )

5) Repeat steps 1-4 for the second image date

6) Generate probability distributions of channel change by randomly sampling a delineation from step 4 for both time periods and overlaying these delineations to create polygons of erosion and deposition; repeat using different $A_{\max } \& A_{\min }$ overlays

7a) $A_{\min (t 1)} \& A_{\min (t 2)}$

7b) $A_{\max (t 1)} \& A_{\max (t 2)}$

7c) $A_{\min (t 1)} \& A_{\max (t 2)}$

7d) $A_{\max (t 1)} \& A_{\min (t 2)}$ 

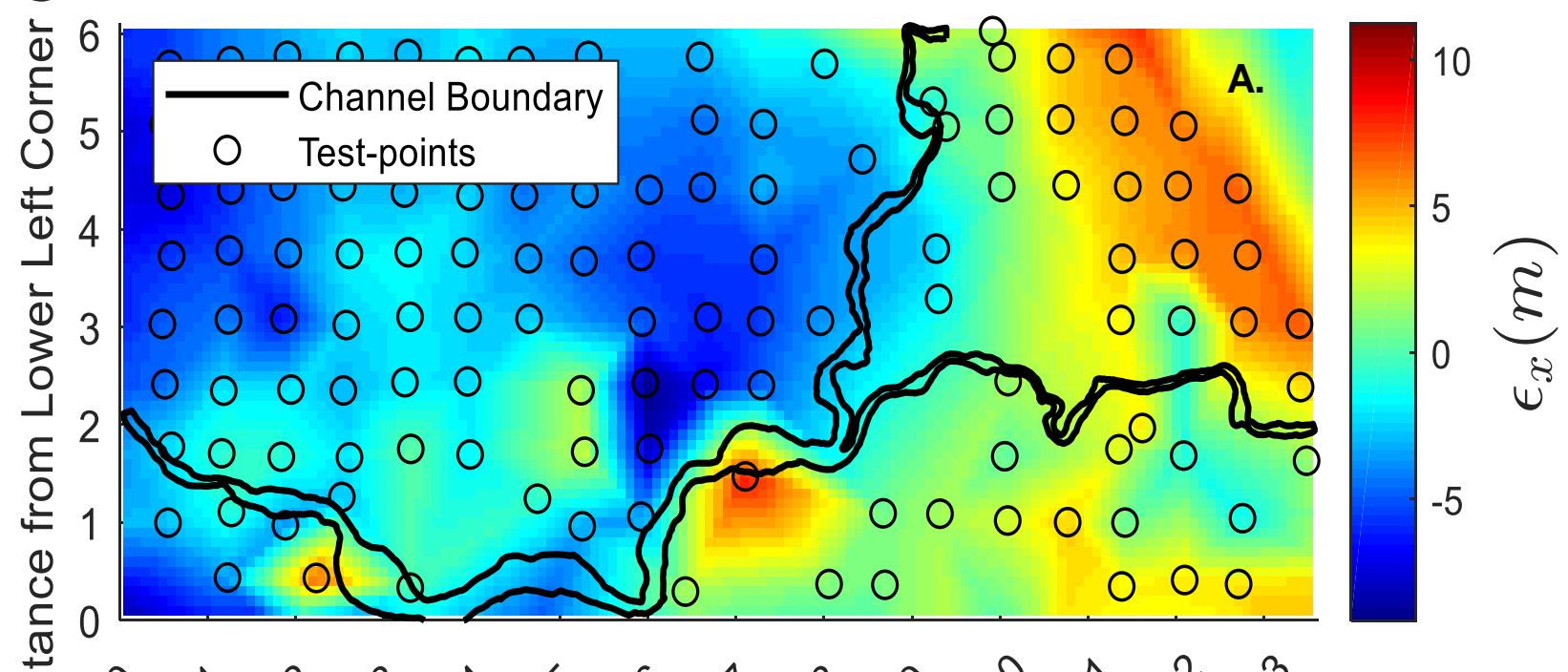

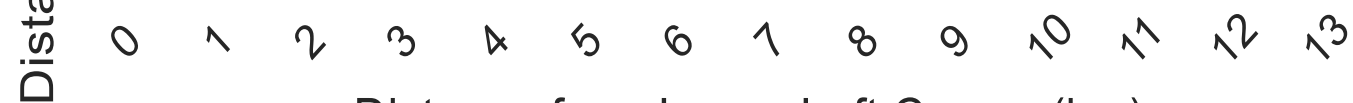

Distance from Lower Left Corner $(\mathrm{km})$
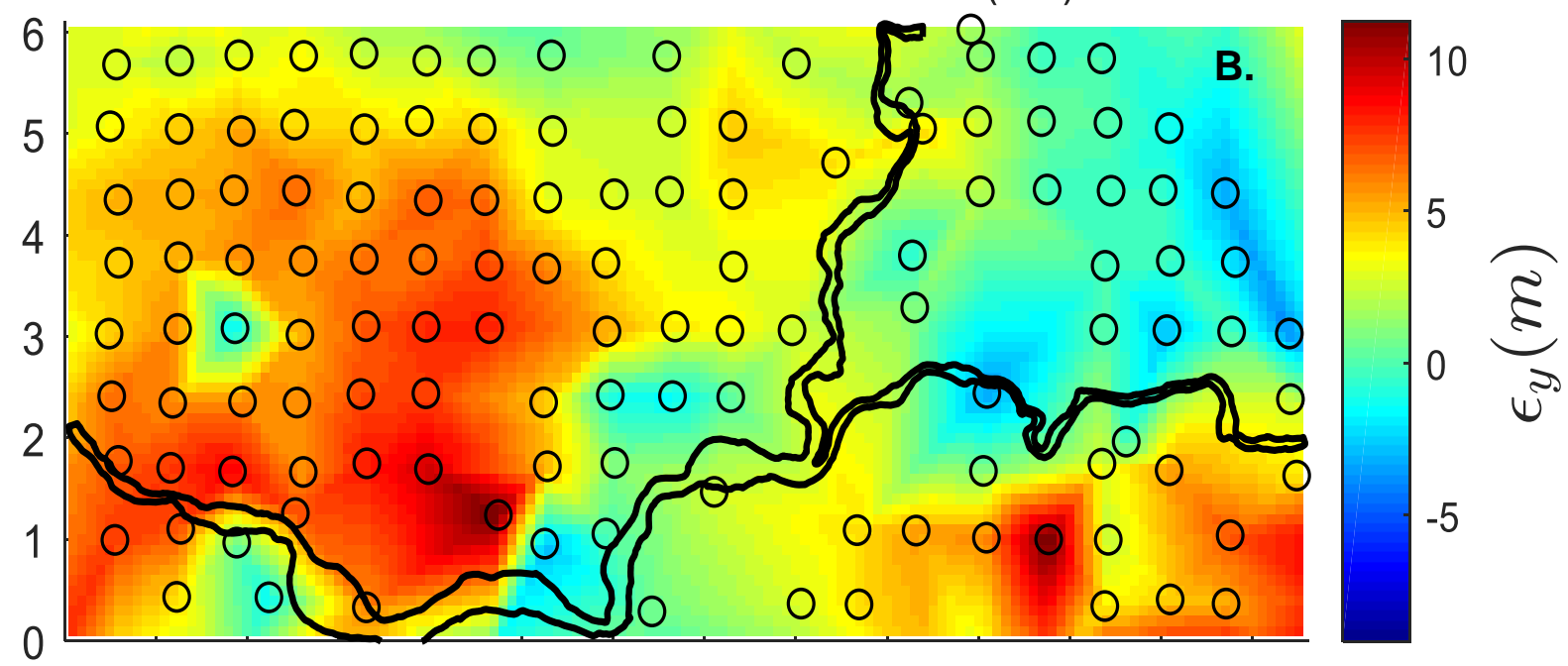

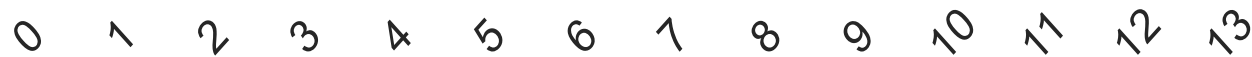
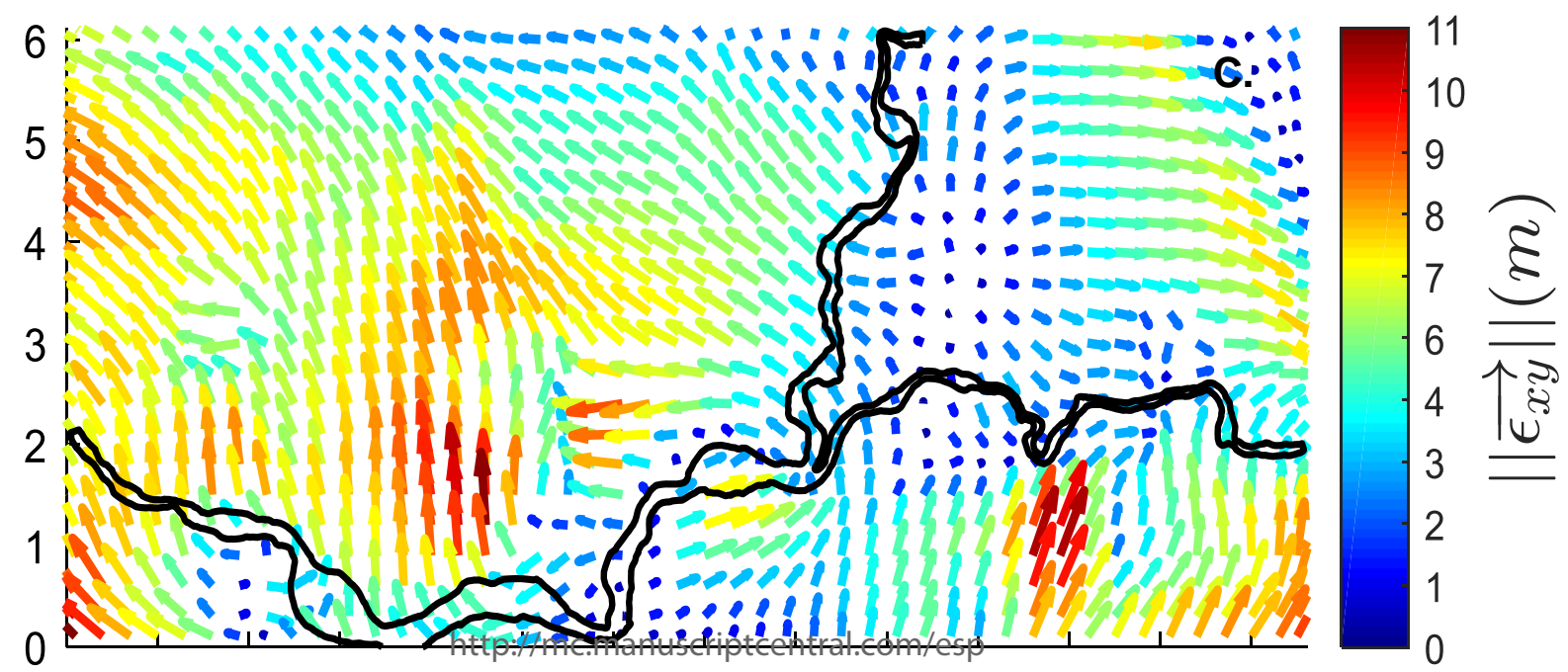

$0 \wedge 23 \times 561891^{0} \wedge^{1} 1^{2} 1^{3}$ 


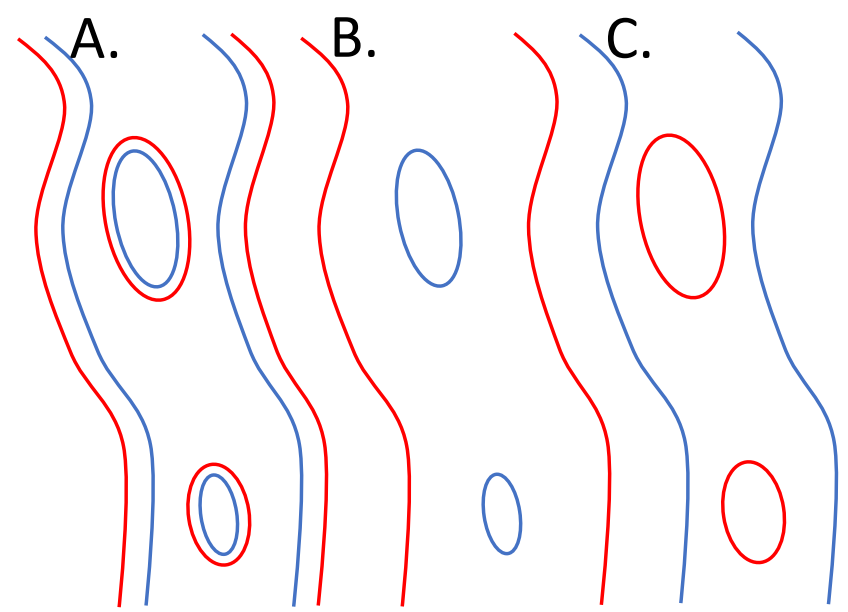

$\sim$ Maximum extent of active channel and vegetated islands $\sim$ Minimum extent of active channel and vegetated islands 

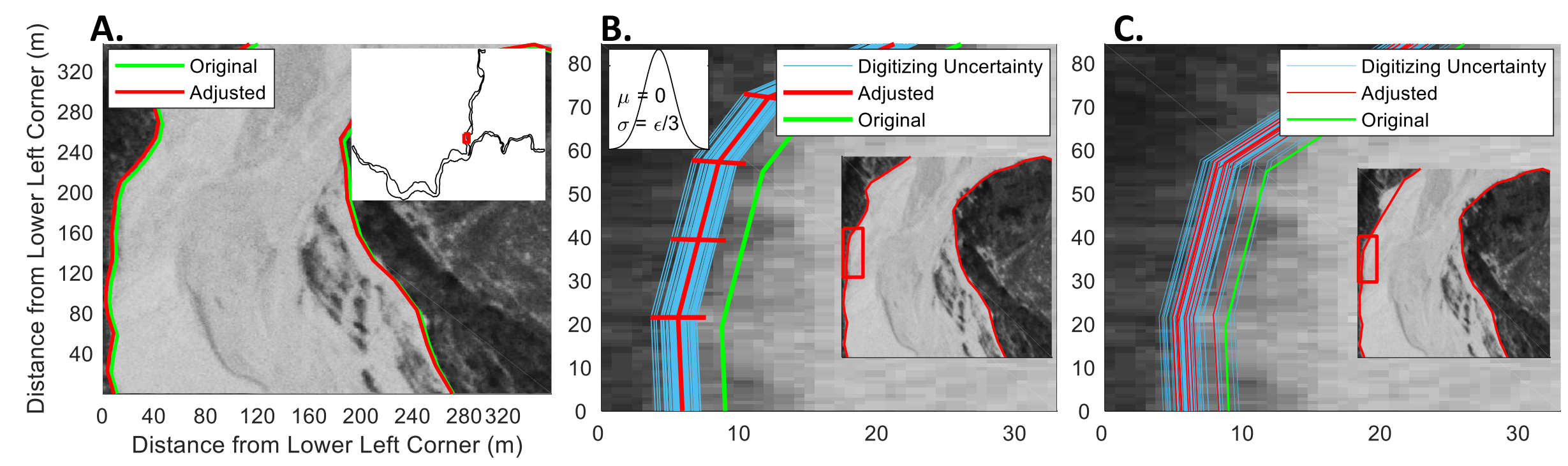


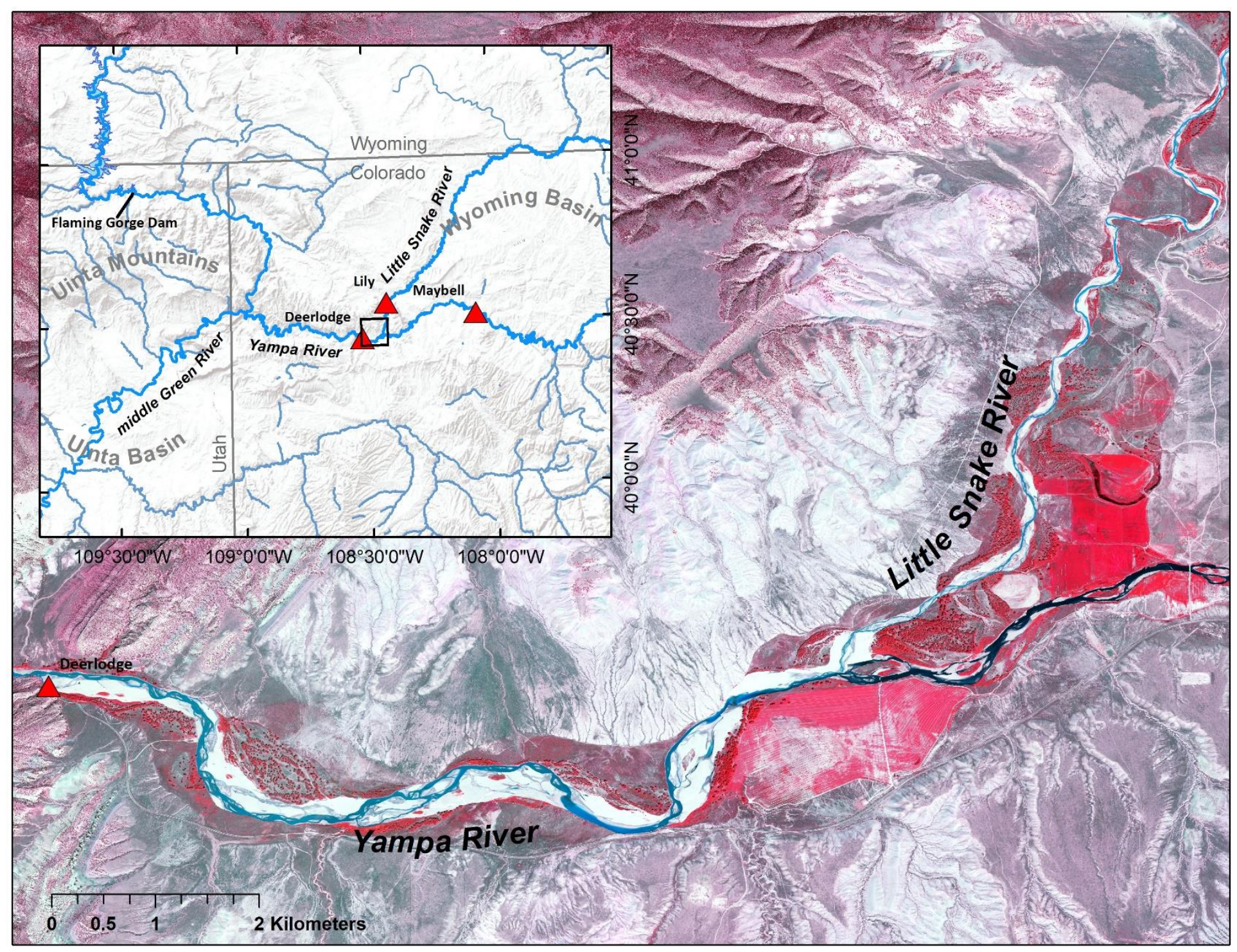

http://mc.manuscriptcentral.com/esp 

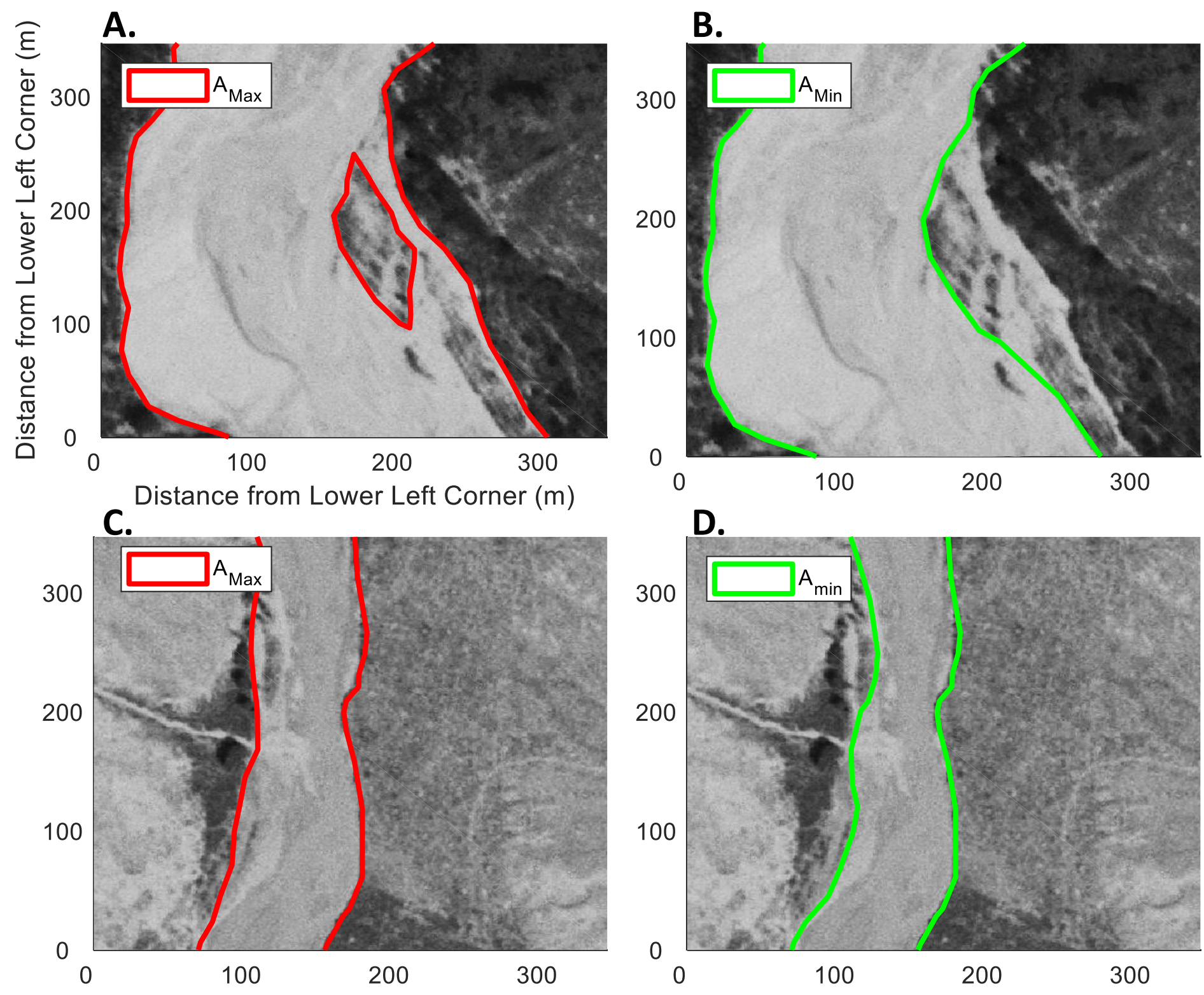

http://mc.manuscriptcentral.com/esp 

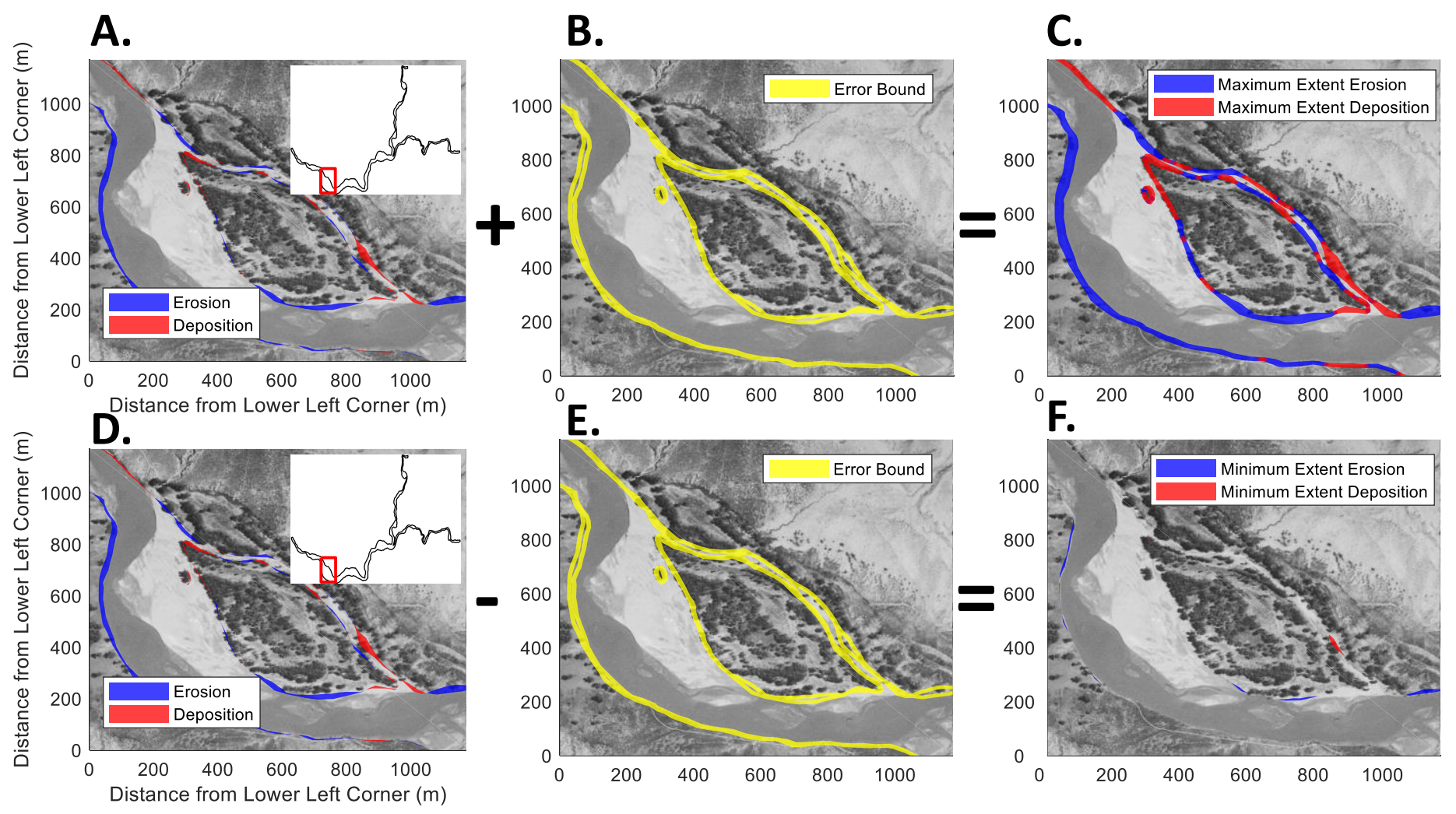


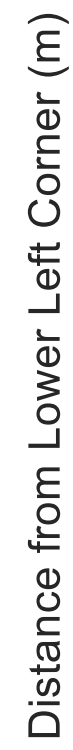

A.
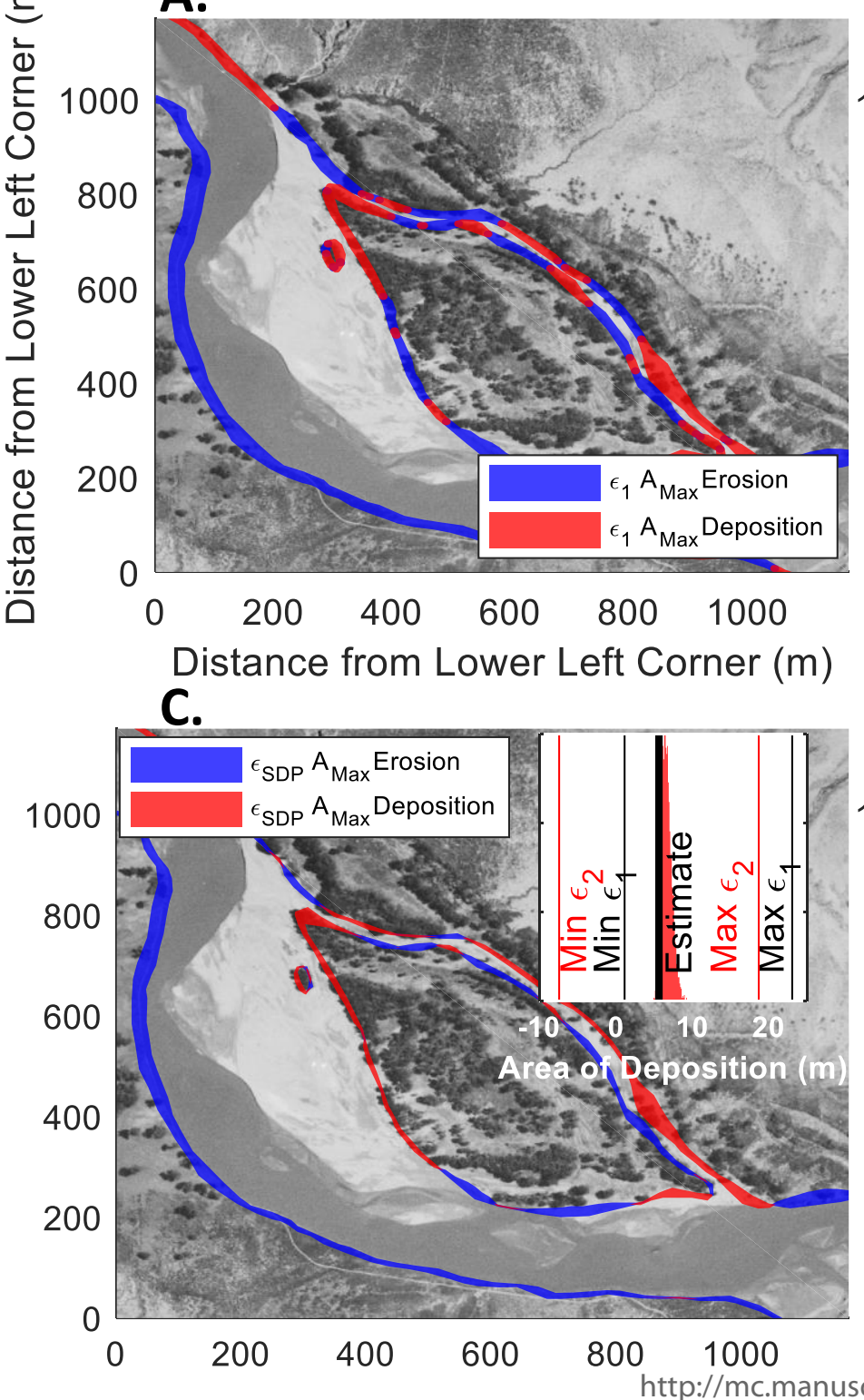

B.

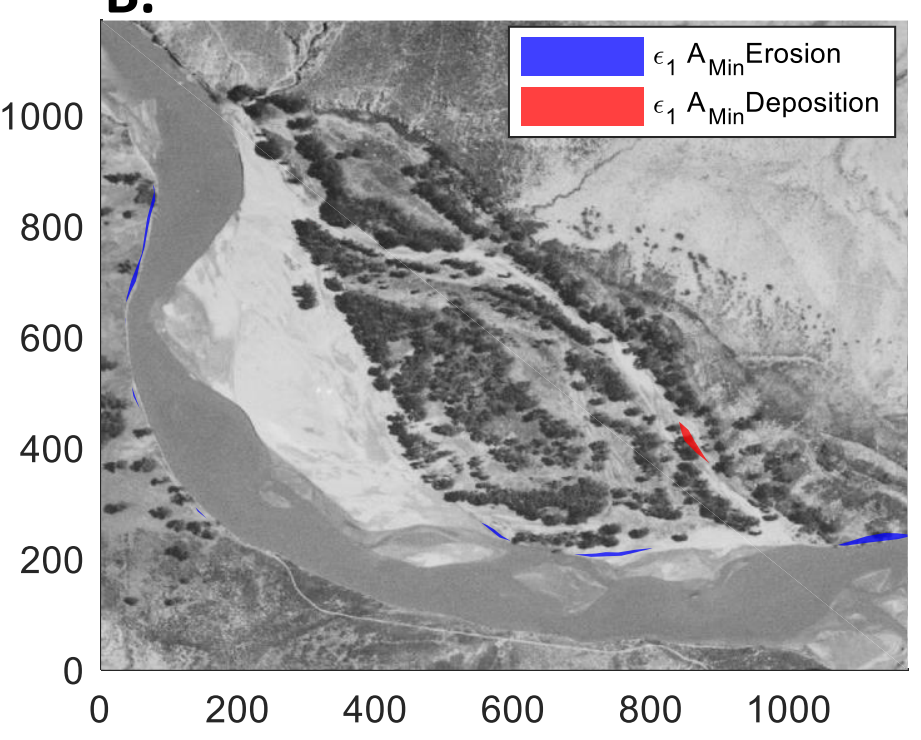

D.

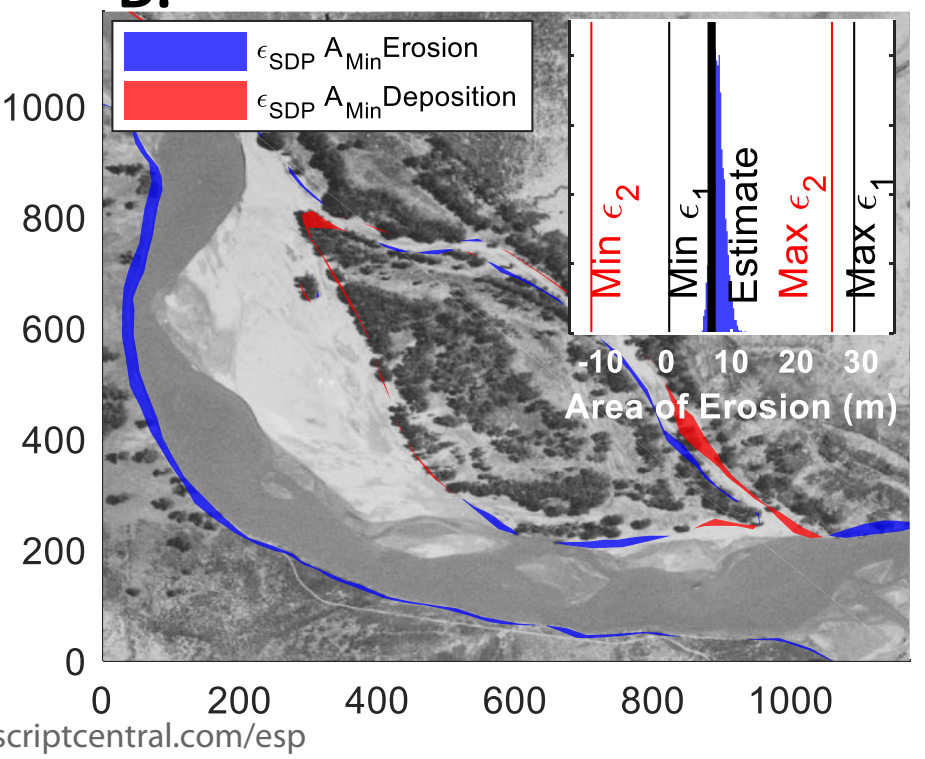




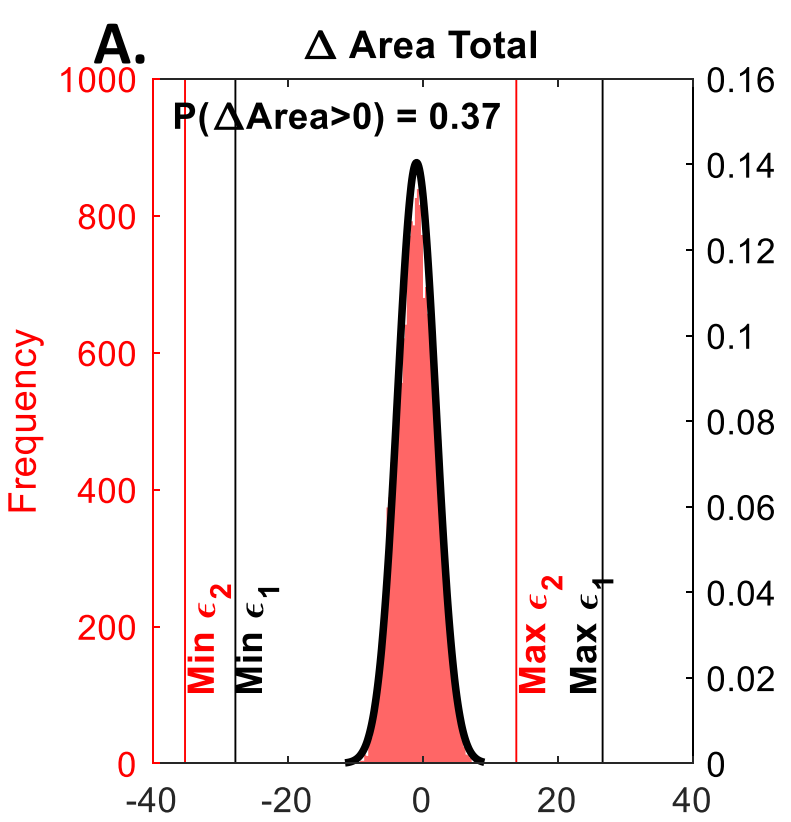

$\Delta$ area per unit channel length $(\mathrm{m})$

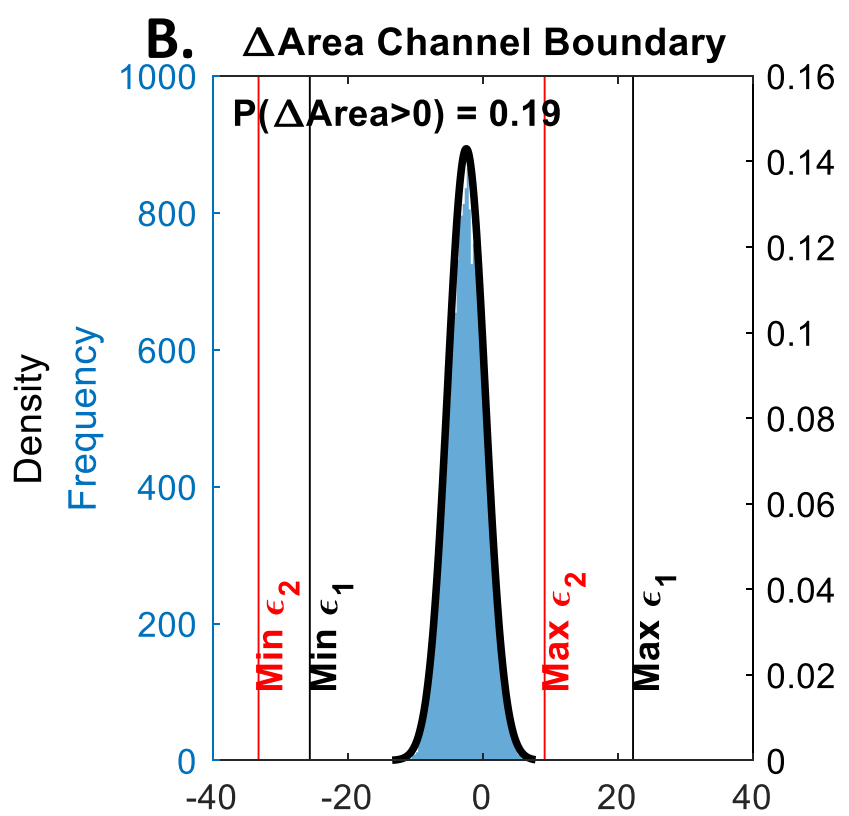

$\Delta$ area per unit channel length $(\mathrm{m})$

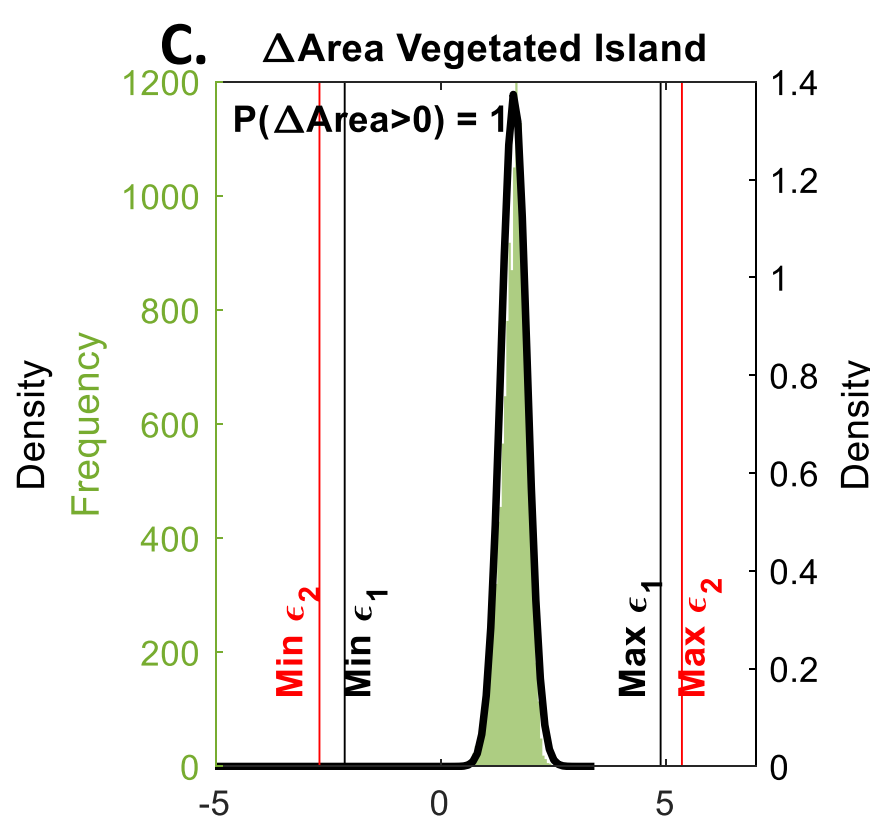

$\Delta$ area per unit channel length $(\mathrm{m})$ 


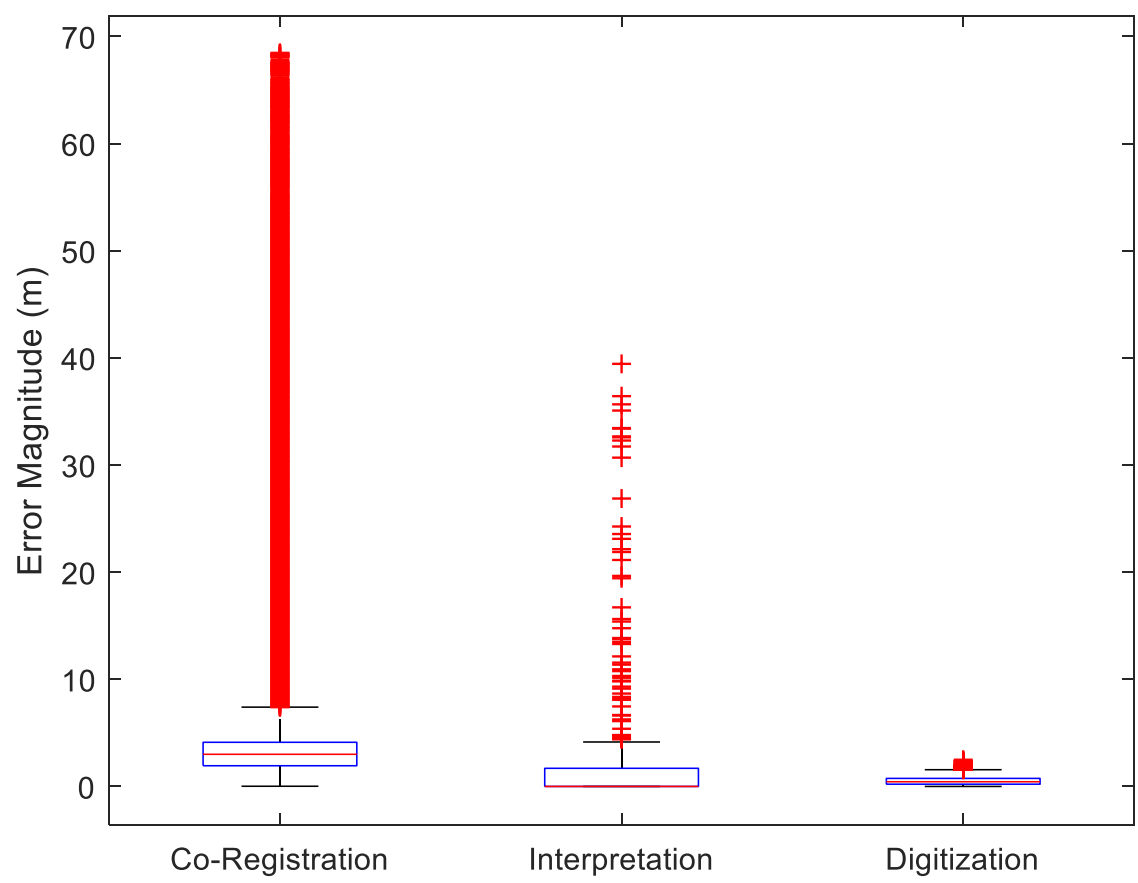


Fig姚e df 112
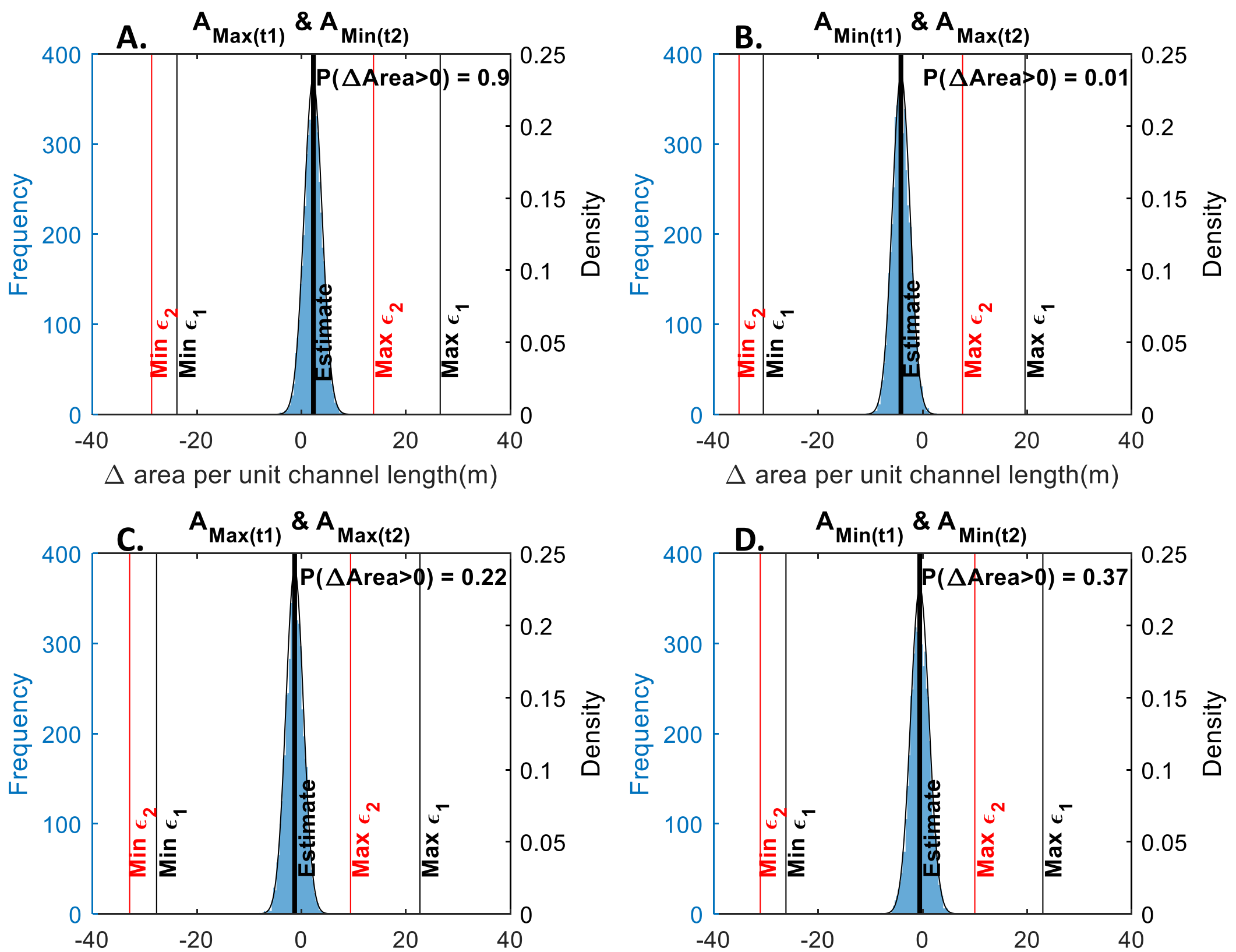

$\Delta$ area per unit channel length $(\mathrm{m})$ the $/ /$ manuscriptcentral.com/esp $\Delta$ area per unit channel length $(\mathrm{m})$ 

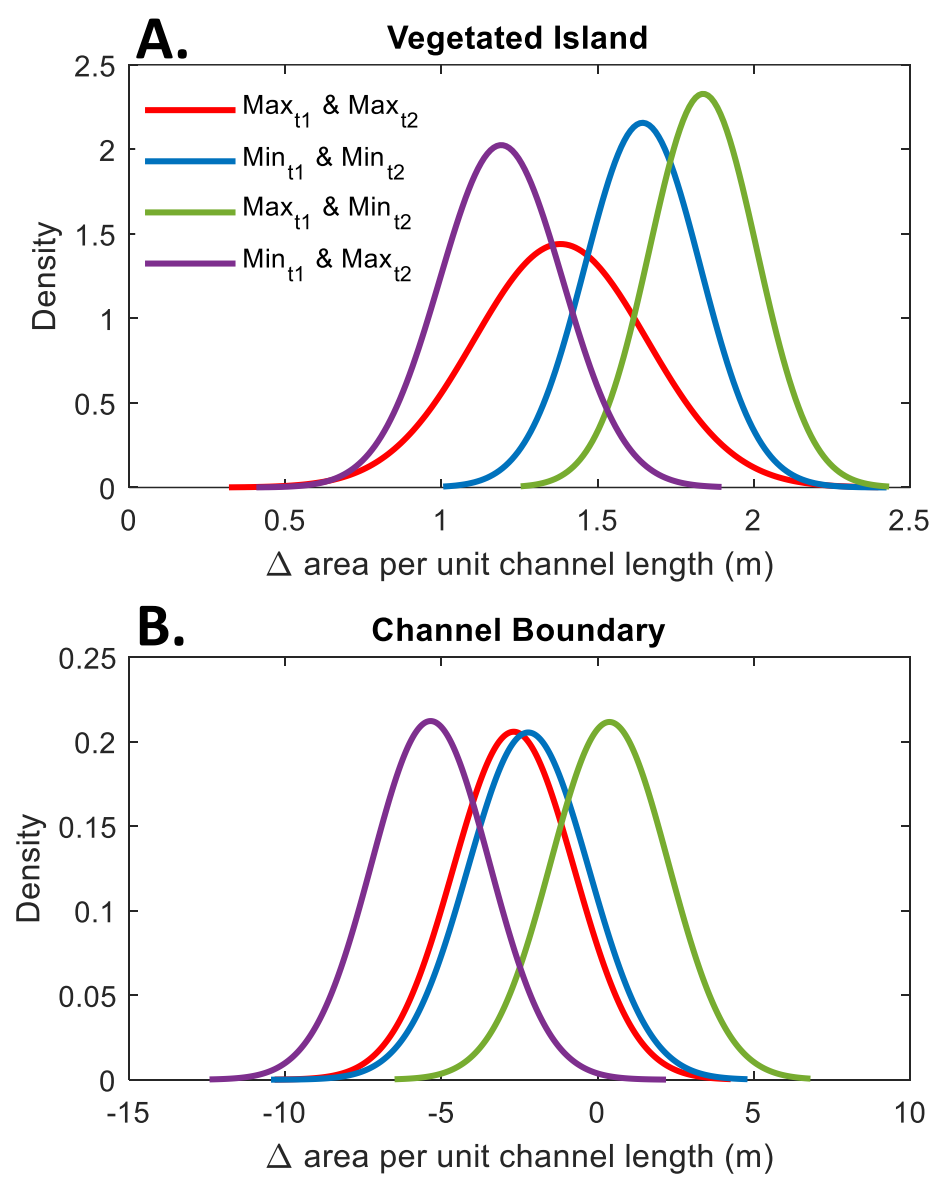

http://mc.manuscriptcentral.com/esp 


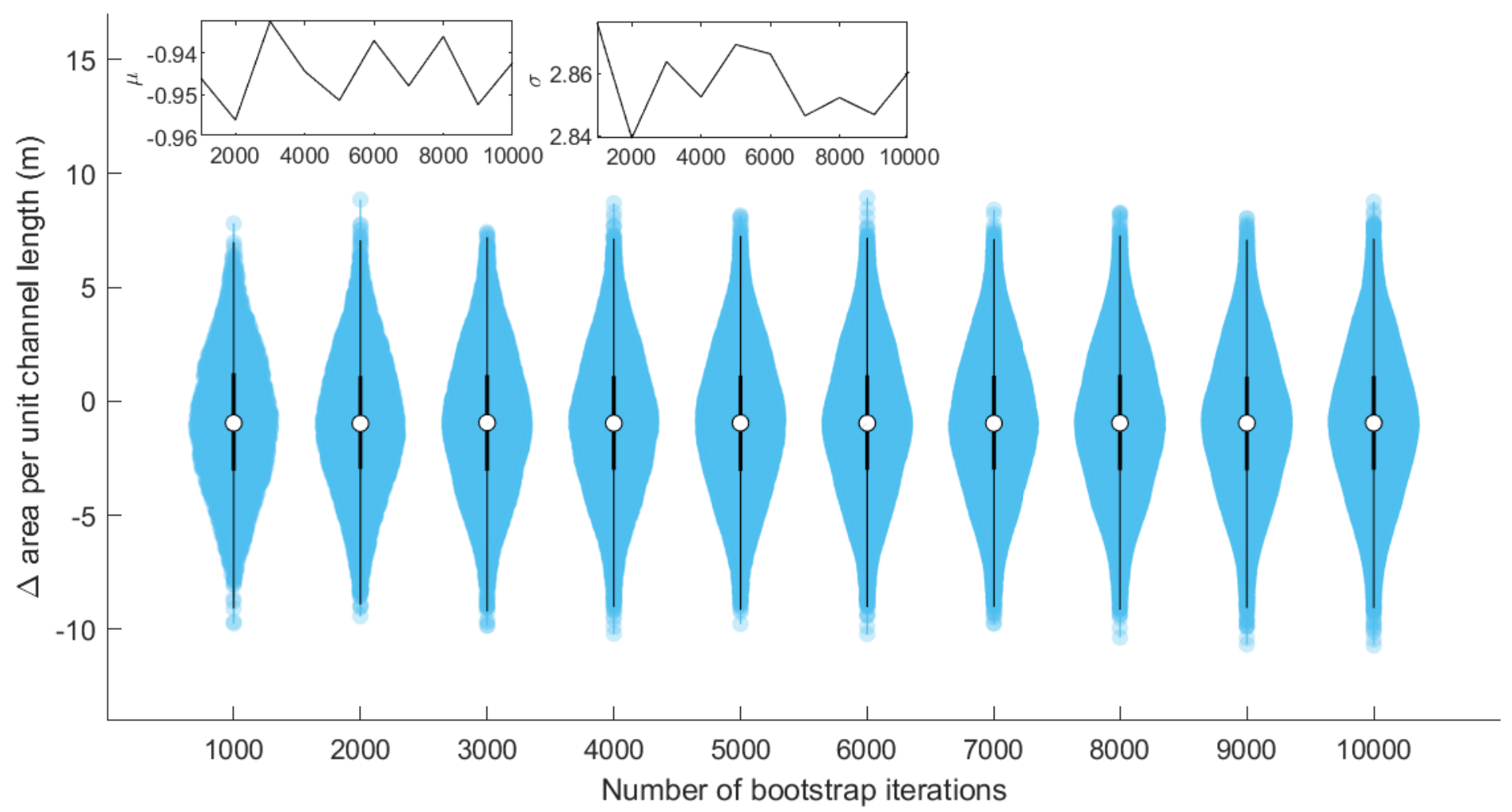



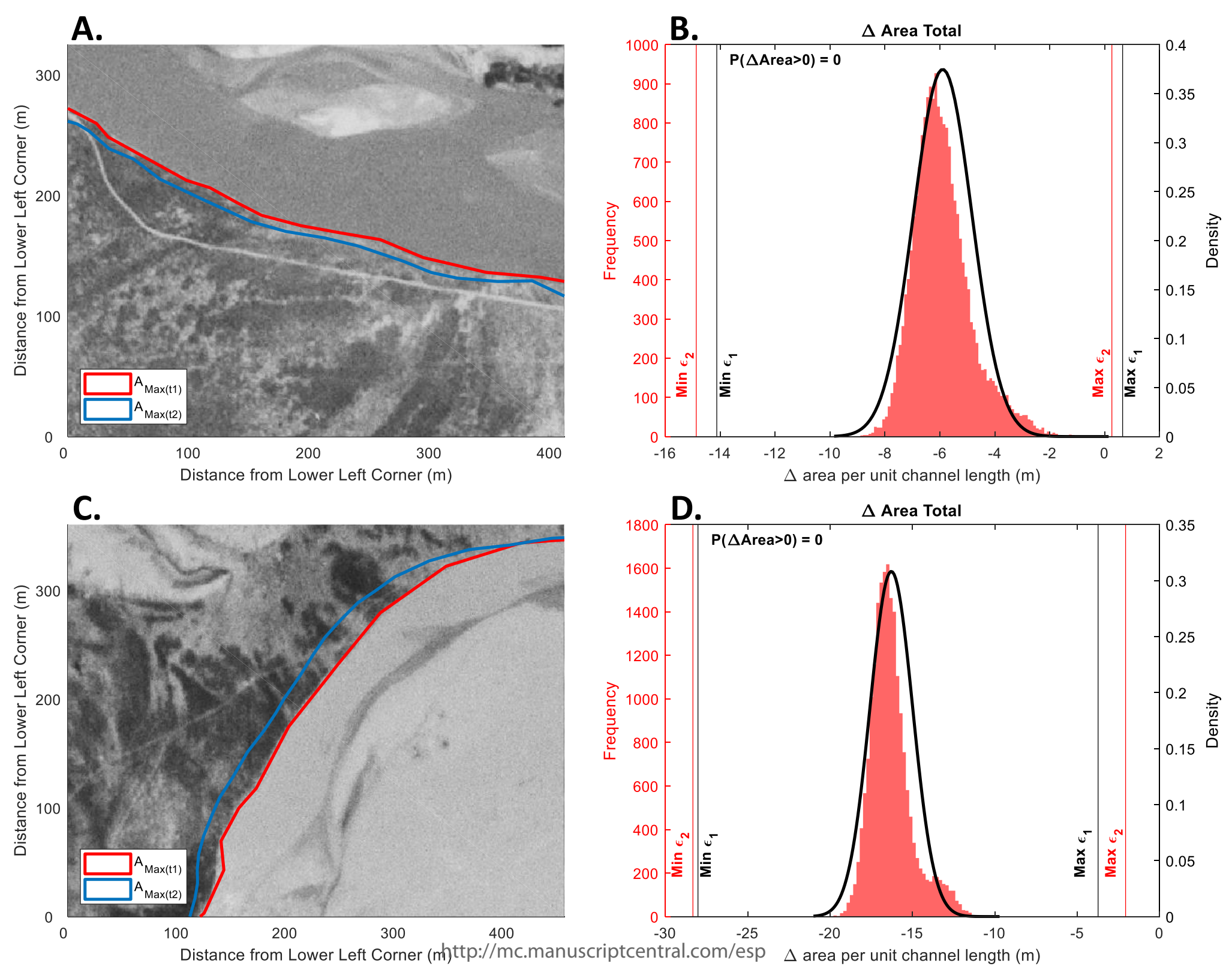

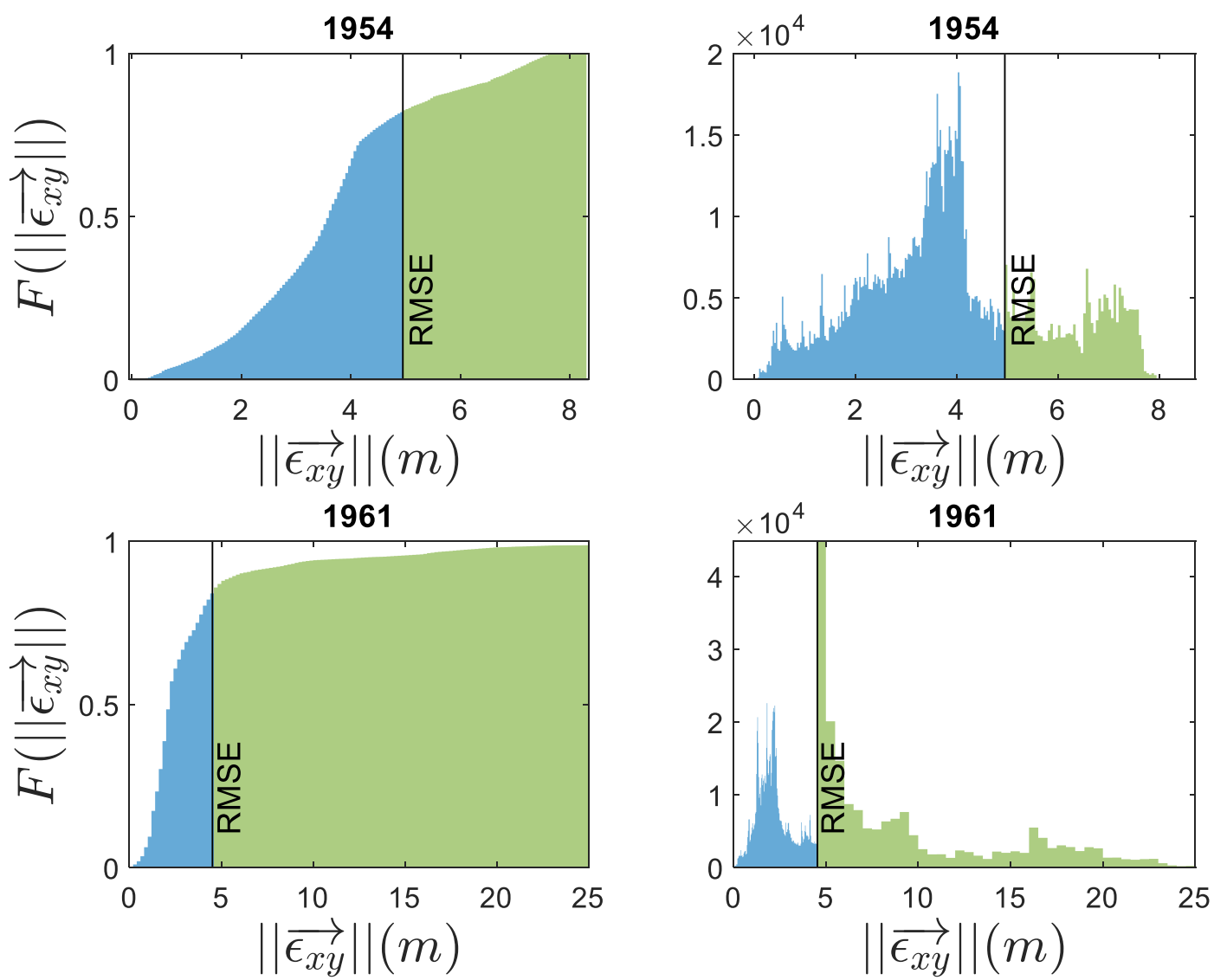


\section{Supplemental Information:}

Step-by-step instructions for SDP Algorithm

1) Image Warping: If the aerial images are not in a real world coordinate system, they must be geo-referenced using image warping. All unregistered images should be warped to the same base image. We refer the reader to Gilvear and Bryant (2003), Mount et al. (2003), and Hughes et al. (2006) for background on image warping.

2) Image co-registration: The image co-registration error can be quantified after the images are in the same coordinate system. We define co-registration error as the misalignment between the image being digitized and the most recent image in the time series (Figure 1 step 1).

a. Independent test-point: Identify test-points by extracting the map coordinate of the same feature on the image that is being digitized and the most recent image in the time series (Figure 1 step 1a). Note that the image co-registration error will be zero when the channel boundary is being delineated from the most recent image.

b. Magnitude of co-registration error: The magnitude of each test-point error is calculated in the $X$ and $Y$ directions by subtracting the test-point coordinate in the image being used to delineate the channel boundary $\left(x_{i}^{\prime}\right.$, $\left.y_{i}\right)$ from the same test-point coordinate in the most recent image $\left(x_{i}, y_{i}\right)$ (Figure step 1b):

$$
\begin{aligned}
\varepsilon_{x i} & =x_{i}-x_{i}^{\prime} ; \\
\varepsilon_{y i} & =y_{i}-y_{i}^{\prime} ;
\end{aligned}
$$

where $\varepsilon_{x i}$ is the magnitude of co-registration error in the $\mathrm{X}$ direction for the $i^{\text {th }}$ test point and $\varepsilon_{y i}$ is the magnitude of co-registration error in the $Y$ direction for the $i^{\text {th }}$ test point. Positive errors in $\varepsilon_{x}$ and $\varepsilon_{y}$ are in the east and north directions.

c. Create an $\varepsilon_{x}$ and $\varepsilon_{y}$ surface: Use bi-linear interpolation between $\varepsilon_{x i}$ and $\varepsilon_{y i}$ to create a continuous surface of $\varepsilon_{x}$ and $\varepsilon_{y}$ over the entire study area (Figure step 1d). 
d. Calculate the magnitude and direction of co-registration error: Using the interpolated surface in step $2 \mathrm{c}$, the magnitude $\left(\left\|\overrightarrow{\varepsilon_{x y}}\right\|\right)$ and direction $(\theta)$ of co-registration error can be calculated for any coordinate pair $\left(x_{j}, y_{j}\right)$ :

$$
\begin{gathered}
\left\|\underset{\varepsilon_{x y}}{\longrightarrow}\right\|=\left(\varepsilon_{x j}{ }^{2}+\varepsilon_{y j}{ }^{2}\right)^{0.5} ; \\
\theta=\tan ^{-1}\left(\frac{\varepsilon_{y j}}{\varepsilon_{x j}}\right) ;
\end{gathered}
$$

where $\varepsilon_{x j}$ and $\varepsilon_{y j}$ are the co-registration errors in the $\mathrm{X}$ and $\mathrm{Y}$ directions at point $\left(x_{j}, y_{\mathrm{j}}\right)$ extracted from the $\varepsilon_{x}$ and $\varepsilon_{y}$ surface in step 2c.

e. Account for the spatial distribution of test-points: The spatial distribution of test-points will affect the interpolation of $\varepsilon_{x}$ and $\varepsilon_{y}$. Therefore, repeatedly withhold $10 \%$ of the test-points using a 10 -fold cross-validation to generate ten $\varepsilon_{x}$ and $\varepsilon_{y}$ surfaces. Using each of the ten interpolated surfaces, repeat steps $2 \mathrm{a}-\mathrm{d}$ to calculate $\left\|\underset{\varepsilon_{x y}}{\rightarrow}\right\|$ and $\theta$ at any $x_{j}, y_{\mathrm{j}}$ point (Figure 1 step 1e).

3) Interpretation uncertainty: Digitize the maximum and minimum active channel and vegetated island boundaries, thereby accounting for uncertainty in interpretation (Figure 1 step 2).

4) Calculate $\left\|\underset{\varepsilon_{x y}}{\rightarrow}\right\|$ and $\theta$ along the boundary delineation: Densify the vertices along the $A_{\max }$ and $A_{\min }$ boundaries from step 3 using an interval that is small enough as to not simplify the $A_{\max }$ and $A_{\min }$ boundaries (e.g., $1 / 10$ the mean channel width) and calculate $\left\|\overrightarrow{\varepsilon_{x y}}\right\|$ and $\theta$ at each vertex using one of the ten $\varepsilon_{x}$ and $\varepsilon_{y}$ surfaces from step $2 \mathrm{e}$.

5) Adjust each vertex by the co-registration error: Move each vertex in step 4 by the magnitude of $\left\|\overrightarrow{\varepsilon_{x y}}\right\|$ in the direction of $\theta$. This step creates a new active channel delineation that is adjusted by the co-registration error in one of the $10 \varepsilon_{x}$ and $\varepsilon_{y}$ surfaces from step $2 \mathrm{e}$ (Figure 1 step 3). 
6) Digitization uncertainty: Digitization uncertainty is estimated probabilistically by randomly sampling 100 values from a normal distribution with a mean of zero and a standard deviation of one third the maximum digitizing uncertainty. The method also includes an option to define the maximum digitizing uncertainty as the number of pixels multiplied by the pixel resolution. For each randomly sampled uncertainty value, the vertices in step 5 are moved along a normal vector with a magnitude given by the uncertainty value (Figure 1 step 4 ). This process generates 100 delineations of the channel boundary.

7) Repeat for all co-registration error surfaces: Repeat steps 4-6 for each coregistration error surface in step $2 \mathrm{e}$. This produces $m X n$ delineations for each maximum and minimum active channel boundary, where $m$ is the number of error surfaces generated in step $2 e$ and $n$ is the number of times that the digitization error is sampled in step 6. In the manuscript example, $m$ is 10 and $n$ is 100 , which generates 1000 delineations of the channel boundary. The $m X n$ delineations represent a probabilistic boundary delineation for $A_{\max }$ and $A_{\min }$.

8) Create probabilistic boundary delineations for a second aerial image: Repeat steps 2-7 for a second image that will be compared to the first to quantify channel change (Figure 1 step 5).

9) Generate probability distributions of channel change: Randomly sample, with replacement, 5000 probabilistic boundary delineations from both aerial images, overlay each sampled boundary to create polygons of erosion and deposition, and repeat using different $A_{\max }$ and $A_{\min }$ overlays (Figure 1 step 6 ). The distribution of areal changes represents the combined uncertainty in coregistration, digitization, and interpretation. $A_{\max }$ and $A_{\min }$ overlays include:

a. Minimum active channel boundary in both images $\left(A_{\left.\operatorname{Min}(11) \& A_{\min (2)}\right)}\right)$; where the subscripts $t 1$ and $t 2$ denote the earlier and later images, respectively (Figure 1 step $7 a$ ).

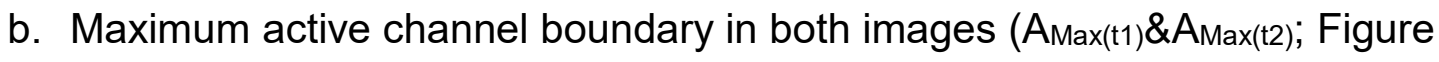
1 step $7 b)$. 
c. Minimum active channel boundary in the earlier image and maximum active channel boundary in the later image $\left(A_{\operatorname{Min}(11)} \& A_{\operatorname{Max}(t 2)}\right.$; Figure 1 step 7c).

d. Maximum active channel boundary in the earlier image and minimum

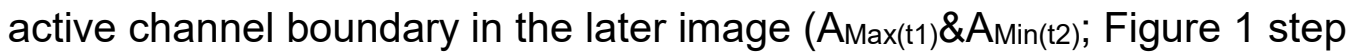
$7 d)$.

References:

Gilvear D, Bryant R. 2003. Analysis of aerial photography and other remotely sensed data. In Tools in Fluvial Geomorphology, Kondolf MG and Piegay H (eds). Wiley: Chichester, U.K.; 135-170.

Hughes ML, McDowell PF, Marcus WA. 2006. Accuracy assessment of georectified aerial photographs: implications for measuring lateral channel movement in a GIS. Geomorphology 74 : 1-16. DOI: 10.1016/j.geomorph.2005.07.001

Mount NJ, Louis J, Teeuw RM, Zukowskyj PM, Stott T. 2003. Estimation of error in bankfull width comparisons from temporally sequenced raw and corrected aerial photographs. Geomorphology 56 : 65-77. DOI: 10.1016/S0169-555X(03)00046-1 